\title{
Observed spatiotemporal variability of boundary-layer turbulence over flat, heterogeneous terrain
}

\author{
V. Maurer ${ }^{1}$, N. Kalthoff ${ }^{1}$, A. Wieser ${ }^{1}$, M. Kohler ${ }^{1}$, M. Mauder ${ }^{2}$, and L. Gantner ${ }^{1}$ \\ ${ }^{1}$ Institut für Meteorologie und Klimaforschung (IMK-TRO), Karlsruher Institut für Technologie (KIT), \\ Karlsruhe, Germany \\ ${ }^{2}$ Institut für Meteorologie und Klimaforschung (IMK-IFU), Karlsruher Institut für Technologie (KIT), \\ Garmisch-Partenkirchen, Germany
}

Correspondence to: V. Maurer (vera.maurer@kit.edu)

Received: 3 June 2015 - Published in Atmos. Chem. Phys. Discuss.: 2 July 2015

Revised: 9 October 2015 - Accepted: 25 January 2016 - Published: 8 February 2016

\begin{abstract}
In the spring of 2013, extensive measurements with multiple Doppler lidar systems were performed. The instruments were arranged in a triangle with edge lengths of about $3 \mathrm{~km}$ in a moderately flat, agriculturally used terrain in northwestern Germany. For 6 mostly cloud-free convective days, vertical velocity variance profiles were calculated. Weighted-averaged surface fluxes proved to be more appropriate than data from individual sites for scaling the variance profiles; but even then, the scatter of profiles was mostly larger than the statistical error. The scatter could not be explained by mean wind speed or stability, whereas time periods with significantly increased variance contained broader thermals. Periods with an elevated maximum of the variance profiles could also be related to broad thermals. Moreover, statistically significant spatial differences of variance were found. They were not influenced by the existing surface heterogeneity. Instead, thermals were preserved between two sites when the travel time was shorter than the large-eddy turnover time. At the same time, no thermals passed for more than $2 \mathrm{~h}$ at a third site that was located perpendicular to the mean wind direction in relation to the first two sites. Organized structures of turbulence with subsidence prevailing in the surroundings of thermals can thus partly explain significant spatial variance differences existing for several hours. Therefore, the representativeness of individual variance profiles derived from measurements at a single site cannot be assumed.
\end{abstract}

\section{Introduction}

The vertical velocity variance, $\overline{w^{\prime 2}}$, is one of the relevant parameters describing the turbulent structure of the convective boundary layer (CBL). Measurements of $\overline{w^{\prime 2}}$ have been analyzed for several decades (e.g. Wyngaard et al., 1971; Panofsky and Mazzola, 1971; Kaimal et al., 1976; Young, 1988). Most of these early investigations were based on aircraft observations. Later, radar wind profiler (e.g., Eymard and Weill, 1988; Angevine et al., 1994; Eng et al., 2003) and more recently, Doppler lidar measurements (e.g. Lothon et al., 2009; Hogan et al., 2009; Ansmann et al., 2010; Lenschow et al., 2012) became available for studying vertical velocity characteristics in the CBL. Both in situ aircraft measurements and ground-based remote sensing have advantages and disadvantages: as aircraft observations are expensive, data are usually available for a small number of flight levels only. The measurements must cover a certain distance; i.e., flight legs must be long enough, to meet the requirements of turbulence statistics (Lenschow and Stankov, 1986; Lenschow et al., 1994) so that the turbulence characteristics on the different levels are not available simultaneously. Ground-based remote sensing observations provide turbulence statistics on different levels at the same time for time periods of typically $1 \mathrm{~h}$ or even longer. However, even if it is assumed that temporal and spatial integration are comparable, i.e., if time can be transformed into space via the mean wind speed (Taylor's hypothesis; Taylor, 1938), lidar measurements are representative of a restricted region only. 
a) Landsat image

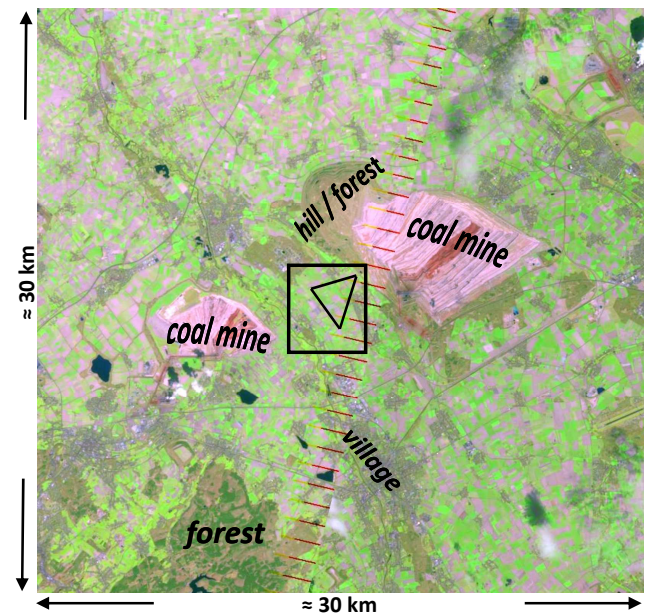

b) land use map

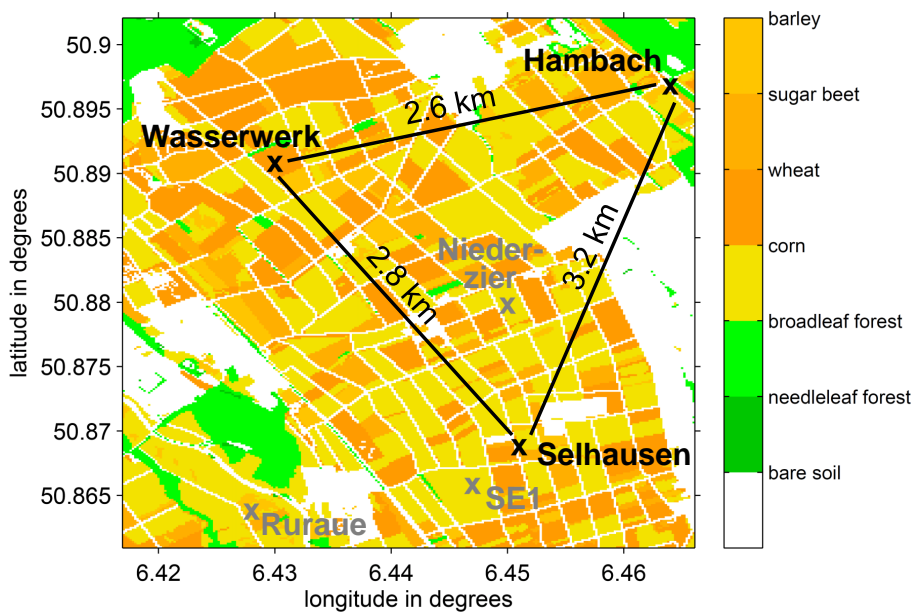

Figure 1. (a) Landsat false color image (composite of infrared and visible bands) from 24 April 2013 (available from the US Geological Survey at landsatlook.usgs.gov); the black rectangle denotes the sector shown in (b); additionally, characteristic topographic features are marked; (b) land-use classification with positions of energy balance stations and lidars at Hambach and Wasserwerk and of the lidar at Selhausen (black crosses) as well as of the TERENO energy balance stations at Ruraue, near Selhausen (SE1), and at Niederzier (gray crosses); black lines denote the relative lidar locations.

In the part of the CBL where buoyant production dominates over the shear production of turbulent kinetic energy, turbulent mixing is supposed to be driven mainly by the heat supply at the Earth's surface. Deardorff (1970a) proposed that for situations with sufficient thermal instability, vertical velocity fluctuations could be scaled by the convective velocity $w_{*}$. Warner (1972), Willis and Deardorff (1974) and Caughey and Palmer (1979) were among the first to present scaled variance profiles, based on laboratory experiments as well as aircraft measurements performed over mainly homogeneous terrain. Large eddy simulations (LES) confirmed the empirical profiles (e.g. Deardorff, 1974; Moeng, 1984; Hadfield et al., 1991). Different fit functions were proposed by Kaimal et al. (1976), Lenschow et al. (1980), or Sorbjan $(1988,1989)$, which reveal a considerable uncertainty. Hogan et al. (2009), e.g., found that scaled variance profiles derived from lidar measurements at one particular site displayed a case-to-case variability that was about as large as the scatter of the fit functions given by Lenschow et al. (1980) and Sorbjan (1986), which had been derived from aircraft measurements. Hence, the uncertainty or representativeness of point measurements is very relevant and becomes even more important for heterogeneous terrain.

Different studies addressed the representativeness of point measurements of turbulent surface fluxes (e.g. Mahrt, 1998; Steinfeld et al., 2007). Others examined sampling errors made by aircraft measurements (e.g. Lenschow and Stankov, 1986; Schröter et al., 2000). Lenschow et al. (1994) considered general statistical errors, including the sampling error, that should be taken into account when calculating turbulence statistics. To our knowledge, no investigation specifi- cally addressed the statistical errors made for simultaneously performed point measurements of vertical turbulence profiles.

During the High Definition Clouds and Precipitation for Climate Prediction $\left(\mathrm{HD}(\mathrm{CP})^{2}\right)$ observational prototype experiment (HOPE) performed in April and May 2013 in the Lower Rhine region in Germany, Doppler lidars were deployed in a triangle in an agriculturally used, moderately flat terrain (Fig. 1).

The length of about $3 \mathrm{~km}$ of the three edges had been chosen such that the lidars at the different sites did not sample the same convective cell at the same time. Hence, the distance between the lidar sites had to be larger than the diameter of the convective cells which are assumed to scale with the CBL depth of 1-2 km (e.g. Deardorff, 1970a; Willis and Deardorff, 1974). On the other hand, the locations had to be close enough to be situated within the area of the given surface heterogeneity. For this configuration, the turbulence characteristics derived from the lidar measurements at the three sites should be similar within the range of statistical errors according to Lenschow et al. (1994).

The aims of this study are to generally analyze the profiles of vertical velocity variance available from HOPE as well as to investigate their spatiotemporal variability. By investigating spatial differences of vertical velocity variance, the representativeness of point measurements of vertical turbulence profiles can be assessed. The paper is structured as follows: in the next section, the observations and the measurement setup are described. Section 3 presents analyses of the vertical velocity measurements and gives an overview of the computation of the vertical velocity variances and con- 
sidered errors. It also includes considerations regarding the normalization procedure. In Sect. 4, scaled vertical velocity variances are described separately for the different sites as well as compared for the three sites, and possible influencing factors are discussed. Finally, Sect. 5 summarizes the main findings.

\section{Overview of the measurements}

\subsection{Measurement site and instruments}

The HOPE measurement area was located near Forschungszentrum Jülich, in the north of a low mountain range (Eifel), with two larger open-pit coal mines (up to $10 \mathrm{~km}$ wide) and several smaller wooded areas in the vicinity (Fig. 1a). All instruments considered here were located within an agriculturally used area near the villages of Hambach and Niederzier (Fig. 1b). The diagonals of the individual fields with various crops are roughly between 100 and $500 \mathrm{~m}$. The Landsat image of April 2013 (Fig. 1a) shows that a part of the crop fields was already covered by vegetation while others were still bare.

As part of HOPE, the Karlsruhe advanced mobile observation platform KITcube (Kalthoff et al., 2013) was installed. Most of the KITcube instrumentation was operated at Hambach $\left(50.897^{\circ} \mathrm{N} / 6.464^{\circ} \mathrm{E}, 110 \mathrm{~m}\right.$ m.s.l.). Additionally, instruments were installed at a second site, called Wasserwerk $\left(50.891^{\circ} \mathrm{N} / 6.430^{\circ} \mathrm{E}, 96 \mathrm{~mm} . \mathrm{s} .1.\right), 2.6 \mathrm{~km}$ west of Hambach. For this study, Doppler lidar data from a site near Selhausen $\left(50.869^{\circ} \mathrm{N} / 6.451^{\circ} \mathrm{E}, 105 \mathrm{~mm} . \mathrm{s} .1\right.$. $)$ and energy balance data from nearby eddy-covariance stations (Graf et al., 2010) of the Terrestrial Network of Observatories (TERENO; Zacharias et al., 2011) were used as well. The instruments whose data are used here are briefly described below.

\subsubsection{Doppler lidars at three sites}

At Hambach, a 1.6- $\mu \mathrm{m}$ heterodyne Doppler lidar (WindTracer "WTX" with an Er:YAG laser, Lockheed Martin Coherent Technologies, Inc.) was deployed. The lidar measures the radial wind velocity via the Doppler shift of radiation scattered at aerosol particles. It can be operated with different scan patterns. Mean horizontal wind speed profiles can be calculated with the velocity-azimuth display (VAD) algorithm (Browning and Wexler, 1968). Applying the vertical stare mode as for this investigation yields vertical velocity $w$ with a time resolution of $1 \mathrm{~s}$ from about $375 \mathrm{~m}$ above ground level (a.g.l.) to the top of the boundary layer and partly above, depending on the aerosol concentration as well as on the measurement setup. Technically, a higher data rate of $10 \mathrm{~Hz}$ would be possible, but a temporal resolution of $1 \mathrm{~Hz}$ is considered the optimal setting for the vertical stare mode, as it ensures higher signal-to-noise ratios by longer averaging. The effective range-gate resolution is about $60 \mathrm{~m}$ (Träumner et al., 2011). The measurements are mainly restricted to the cloud-free atmosphere, because the radiation emitted by the lidar is attenuated within clouds. In order to cover the range between the top of the surface layer and the lowest measurement heights of WTX, a Doppler lidar (WLS7-V2, Leosphere, hereafter called WLS7) with a wavelength of $1.5 \mu \mathrm{m}$ was used. This instrument is capable to measure radial velocity at distances between 40 and $400 \mathrm{~m}$ with a range resolution of $20 \mathrm{~m}$. As for WTX, operation of the system in the vertical stare mode allows for the direct detection of vertical velocity. In combination with the WindTracer WTX at Hambach, a full vertical coverage of vertical velocity from the top of the surface layer up into the entrainment zone results.

Two Doppler lidars (a $2 \mu \mathrm{m}$ lidar called WindTracer "HYB" with a Tm:LuAG laser/Lockheed Martin CT, and WLS200/Leosphere) were operated at Wasserwerk. Apart from the different laser transmitters, the HYB has similar system settings as the WTX. The Doppler lidar at Selhausen, the third site, was a Stream Line system manufactured by HALO Photonics Ltd. (Pearson et al., 2009, hereafter called HALO), which measures with a range-gate length of $18 \mathrm{~m}$ (Eder et al., 2015). In contrast to the WindTracer systems having a laser pulse of high energy, the HALO and the WLS200 operate in a "low-pulse energy/high-pulse rate mode" and they can resolve the lowest hundreds of ma.g.l. An overview of the lidar instruments at the different locations is also given in Table 1. The variability of the threshold of signal-to-noise ratio taken for filtering noisy data for the different instruments is also related to the different technical specifications. The measurement frequency of $1 \mathrm{~Hz}$ was the same for all Doppler lidars and the measurement settings were chosen such that vertical velocity data were available at intervals of $25 \mathrm{~m}$ for the WindTracer systems as well as for the systems from Leosphere. For the WindTracer systems, this setup causes an overlap of the effective range gates. The data of HALO were interpolated to the same heights.

As all heights used in this study will be in m a.g.l., we will omit the adjunct "a.g.l." in the following sections.

\subsubsection{Energy balance stations}

The energy balance stations measure solar and reflected irradiance, long-wave incoming and outgoing radiation, soil heat, sensible heat, latent heat, and momentum fluxes. For the turbulent fluxes, temperature, humidity, and wind speed are measured with an ultrasonic anemometer/thermometer and a fast infrared hygrometer at a height of $4 \mathrm{~m}$. All turbulent fluxes used in this study were calculated for time intervals of 30 min using the eddy-covariance software package TK3.11 of Mauder and Foken (2011) and Mauder et al. (2013). Altogether, data of five energy balance stations were used: two energy balance stations of KITcube that were co-located with the lidar instruments at Hambach and at the Wasserwerk site and three TERENO stations at Niederzier, Selhausen, and Ruraue (Fig. 1b). 
Table 1. Overview of lidar instruments at the three sites, with abbreviations used in the text, measurement range $r$ for the vertical stare mode, range-gate length $\Delta r$, and applied threshold of signal-to-noise ratio (SNR; $w$ measurements with SNR below the threshold were not used in this study); $n / c$ for "not communicated", * according to Pearson et al. (2009).

\begin{tabular}{|c|c|c|c|c|c|}
\hline Lidar & HYB & WLS200 & HALO & WTX & WLS7 \\
\hline Location & Wasserwerk & Wasserwerk & Selhausen & Hambach & Hambach \\
\hline Specification & WindTracer & WINDCUBE 200s & Stream Line & WindTracer & WINDCUBE v2 \\
\hline Manufacturer & Lockheed Martin CT & Leosphere & Halo Photonics & Lockheed Martin CT & Leosphere \\
\hline Laser wavelength in $\mathrm{nm}$ & 2023 & 1543 & $\approx 1500$ & 1617 & 1543 \\
\hline$r$ in m a.g.l. & 350 - above CBL top & $50-\mathrm{CBL}$ top & $60-\mathrm{CBL}$ top & $350-\mathrm{CBL}$ top & $40-290$ \\
\hline$\Delta r$ in $\mathrm{m}$ & $\approx 60$ & 25 & 18 & $\approx 60$ & 25 \\
\hline SNR threshold in $\mathrm{dBZ}$ & -8 & -26 & -16 & -8 & -22 \\
\hline $\begin{array}{l}\text { Pulse repetition fre- } \\
\text { quency in } \mathrm{kHz}\end{array}$ & 0.50 & $n / c$ & 15 & 0.75 & 30 \\
\hline Sampling rate in $\mathrm{MHz}$ & 250 & $n / c$ & $30^{*}$ & 250 & 250 \\
\hline
\end{tabular}

\subsubsection{Additional instruments at Hambach}

To obtain vertical profiles of temperature, humidity, wind speed, and wind direction, the KITcube radiosonde system (DFM-09, Graw) was operated at Hambach. On 18 days selected as intensive operation periods (IOPs), radiosondes were launched every $2 \mathrm{~h}$. On all other days, launches were done at least at 11:00 and 23:00 UTC. A microwave radiometer (HATPRO, Radiometer Physics GmbH) was also operated at Hambach. The instrument detects thermal radiation emitted by atmospheric components. From these data, for example time series of integrated water vapor (IWV) can be derived with high accuracy (Pospichal and Crewell, 2007). An additional ultrasonic anemometer was installed on a mobile tower and measured wind components and virtual temperature at a height of $30 \mathrm{~m}$. Finally, a ceilometer (CHM 15k, Jenoptic) measured cloud-base heights.

\subsection{Selected days}

On 6 days with mainly cloud-free CBL conditions, at least one lidar at each site was configured for $w$ measurements: 18, 20, 22, and 24 April as well as 04 and 19 May. All of these days, apart from 22 April, were also IOP days. Here, the variance profiles for the 6 days were analyzed. From the radiosoundings, mean CBL conditions were estimated (included in Table 2): on 4 of the 6 days, the main regime was governed by westerly to southwesterly flow. On 20 April, the mean wind direction was from the northeast and on 19 May, it varied between northeast to north in the CBL, while it was from the east directly above the CBL. Wind speed was low on 22 April $\left(4 \mathrm{~m} \mathrm{~s}^{-1}\right)$, high on 18 April $\left(12 \mathrm{~m} \mathrm{~s}^{-1}\right)$, and moderate on the remaining days. The Obukhov length $L$ (Monin and Obukhov, 1954) was calculated from averaged values of available energy balance measurements of kinematic sensible heat flux at the surface and friction velocity. As expected in the CBL, $L$ was negative for all days. According to mean wind speeds, its absolute value was highest on 18 April and lowest on 22 April, indicating that turbulence production by wind shear may have been more important on 18 April than on the other days.

As indicated by microwave radiometer measurements, the IWV was moderately high on most days and much higher on 24 April. Incoming shortwave radiation, as measured by a pyranometer network operated by TROPOS (Leipzig), naturally increased from 18 April to 19 May. At the same time, the spatial standard deviation of incoming radiation, in combination with ceilometer data and cloud camera images, revealed the existence of some CBL clouds on 18 April and of altocumulus clouds at about $5 \mathrm{~km}$ on 19 May. Cirrus clouds at about $8 \mathrm{~km}$ existed on 24 April, but they did not affect incoming radiation. In comparison to the other days, the maximum sensible heat flux was reduced on 19 May. The height of the capping inversion of the CBL was also lowest on 19 May, while it was highest on 18 April. As indicated by the temporal evolution of temperature profiles of the radiosondes for 18 April (not shown), when the boundary layer grew into this neutral layer, its height increased abruptly from 700 at 09:00 UTC to $1600 \mathrm{~m}$ at 11:00 UTC. This also may have contributed to the formation of some boundary-layer clouds on this day as the sudden mixing throughout the deepened CBL led to a cooling of the former residual layer.

\subsection{Turbulent surface fluxes}

An overview of the daily averaged Bowen ratios (ratio of sensible heat flux to latent heat flux, both averaged over 09:0015:00 UTC) indicates that the values were very high (up to 4) for some stations until 6 May 2013, but below one at all stations after that date (Fig. 2a). Accordingly, values of daily averaged sensible heat flux were highest (up to $220 \mathrm{~W} \mathrm{~m}^{-2}$ ) until 6 May (Fig. 2b).

The Bowen ratio was below one at Selhausen and Ruraue during all the time so that spatial heterogeneity within the respective area of about $5 \mathrm{~km} \times 5 \mathrm{~km}$ existed in April until early May. The rain gauge measurements at Wasserwerk (Fig. 2c) 
Table 2. Overview of characteristic mean values and scales for all considered days (spatially averaged for surface measurements and turbulence characteristics, Hambach for other variables): Diurnal maximum of surface sensible heat flux $H_{0}$ and of boundary-layer height $z_{i}$; daily mean values of integrated water vapor IWV, of spatial mean and standard deviation of incoming shortwave radiation $Q_{\mathrm{SW}}$, in, of mean boundary-layer wind speed $|\boldsymbol{v}|$, and of wind direction; diurnal maximum of convective velocity scale $w_{*}$, of corresponding convective time scale $t_{*}$, and diurnal mean of Obukhov length $L$; estimated peak wavelength of turbulence spectra in 600 m height (10:00-17:00 UTC), $\lambda_{p, w}=|\boldsymbol{v}| f_{p, w}^{-1}$ (using Taylor's hypothesis), with time scale $T_{p, w}=f_{p, w}^{-1}$, and the period $T$ of the autocorrelation function with correspond-

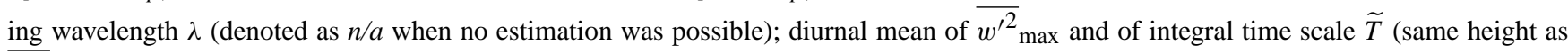
\left.${\overline{w^{\prime 2}}}_{\max }\right)$.

\begin{tabular}{|c|c|c|c|c|c|c|}
\hline & $18 / 04$ & $20 / 04$ & $22 / 04$ & $24 / 04$ & $04 / 05$ & $19 / 05$ \\
\hline$|\boldsymbol{v}|$ in $\mathrm{ms}^{-1}$ & 12 & 8 & 4 & 5 & 8 & 5 \\
\hline Wind dir. in ${ }^{\circ}$ & 250 & 45 & 270 & 270 & 270 & $0-90$ \\
\hline IWV in $\mathrm{kg} \mathrm{m}^{-2}$ & 12 & 8 & 8 & 20 & 10 & 10 \\
\hline$Q_{\mathrm{SW}, \text { in }}$ in $\mathrm{W} \mathrm{m}^{-2}$ & 460 & 490 & 510 & 520 & 560 & 580 \\
\hline$\sigma\left(Q_{\mathrm{SW}, \text { in }}\right)$ in $\mathrm{W} \mathrm{m}^{-2}$ & 100 & 60 & 30 & 60 & 30 & 90 \\
\hline$H_{0}$ in $\mathrm{W} \mathrm{m}^{-2}$ & 200 & 210 & 180 & 180 & 200 & 90 \\
\hline$z_{i}$ in $\mathrm{m}$ & 2030 & 1350 & 1900 & 1330 & 1280 & 1250 \\
\hline$w_{*}$ in $\mathrm{ms}^{-1}$ & 2.10 & 1.92 & 1.86 & 1.70 & 1.82 & 1.45 \\
\hline$t_{*}$ in $\min$ & 15 & 11 & 16 & 12 & 11 & 15 \\
\hline$-L$ in $\mathrm{m}$ & 125 & 34 & 5 & 30 & 51 & 37 \\
\hline \multicolumn{7}{|l|}{ Peak of spectra: } \\
\hline$T_{p, w}$ in $\min$ & $n / a$ & 5.5 & 8 & 8 & 5 & $n / a$ \\
\hline$\lambda_{p, w}$ in $\mathrm{km}$ & $n / a$ & 2.7 & 2 & 2.5 & 2 & $n / a$ \\
\hline \multicolumn{7}{|c|}{ Period of autocorrelation function: } \\
\hline$T$ in $\min$ & $n / a$ & $6-10$ & 15 & 10 & $n / a$ & 6 \\
\hline$\lambda$ in $\mathrm{km}$ & $n / a$ & $2.8-4.4$ & 3.6 & 3 & $n / a$ & 1.8 \\
\hline$\overline{w^{\prime 2}}$ max in $\mathrm{m}^{-2} \mathrm{~s}^{-2}$ & 1.65 & 1.55 & 1.2 & 0.95 & 1.1 & 1.05 \\
\hline$\widetilde{T}$ in $\mathrm{s}$ & 40 & 47 & 55 & 56 & 40 & 45 \\
\hline
\end{tabular}

reveal that there was much less rainfall during this period than after 6 May. From the land-surface point of view, the whole measurement period may be divided into a drier period with considerable spatial heterogeneity and a wetter period with less heterogeneity. Similar differences of Bowen ratio between a wet and a dry period were found during the field experiment LITFASS-2003, which also took place in an area dominated by agricultural land use (Beyrich and Mengelkamp, 2006).

In order to derive spatially representative values of sensible heat flux, an average of flux measurements was calculated by weighting each station with the fraction of the respective land-use class in an area of $30 \mathrm{~km} \times 30 \mathrm{~km}(50.7511-$ $51.0209^{\circ} \mathrm{N} / 6.2366-6.6654^{\circ} \mathrm{E}$ ) with the locations of the lidar instruments in its center. This corresponds to an upstream distance from the measurement sites which the airflow of $4 \mathrm{~m} \mathrm{~s}^{-1}$ passes during $1 \mathrm{~h}$. The land-use map was available at a horizontal resolution of $15 \mathrm{~m} \times 15 \mathrm{~m}$. Not for every landuse class, an energy balance station was available, so that the land-use classes were combined to the following three classes: (1) bare soil/coniferous forest, (2) crops, and (3) meadow/broadleaf forest, with fractions of 31.6, 50.9, and $12.3 \%$, respectively. As the growth of the sugar beets at
Niederzier was not yet advanced in the spring of 2013, the fluxes were considered to be representative of bare soil (class 1), even though the station was located in a field of sugar beets. The stations Selhausen and Wasserwerk (crops) were assigned to class (2) and Ruraue and Hambach (meadow) to class (3). The weighted-averaged flux as well as the Bowen ratio are shown in Fig. 2.

\section{Vertical velocity measurements and variance calculations}

\subsection{Characteristics of vertical velocity data}

As an example, vertical velocity measurements from 11:00 13:00 UTC on 20 April at the three sites are shown for comparison (Fig. 3). Up- and downdrafts with a maximum vertical velocity of more than $2.5 \mathrm{~m} \mathrm{~s}^{-1}$, which are typical of CBLs, were observed at all sites. The thermals lasted for several minutes and rose up to $1200 \mathrm{~m}$ during this time period. The isolines of potential temperature of 283-285 K (Fig. 3b) display the height of the inversion layer at $1200 \mathrm{~m}$, which also agrees with the measurement heights of the lidars WTX 
(a) Bowen ratio

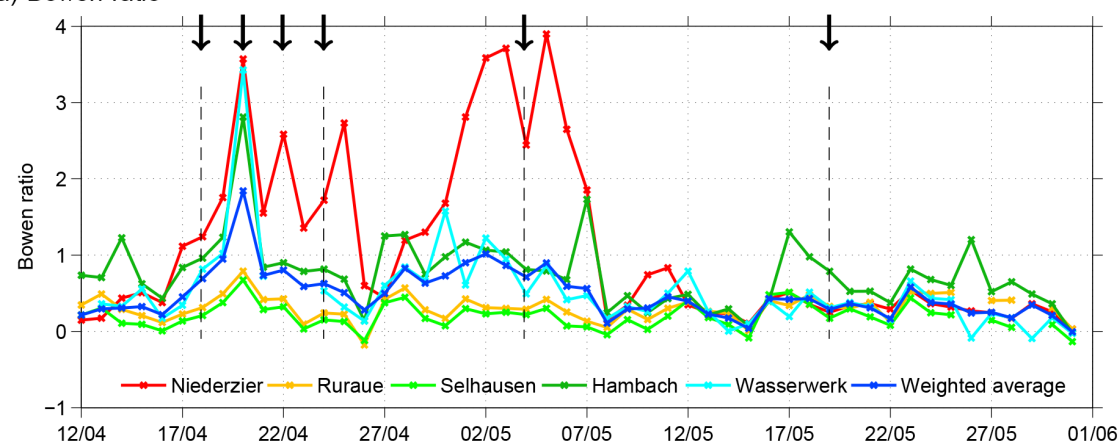

(b) Sensible heat flux

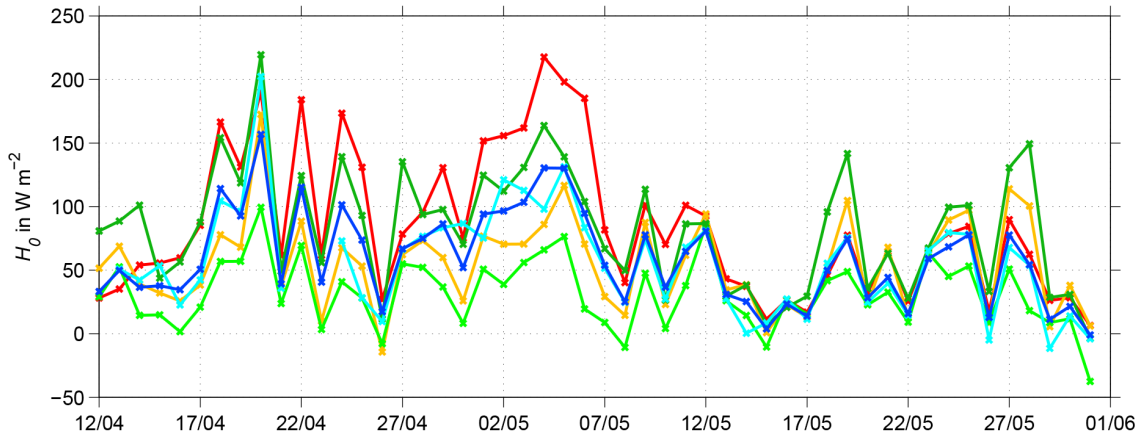

(c) Precipitation

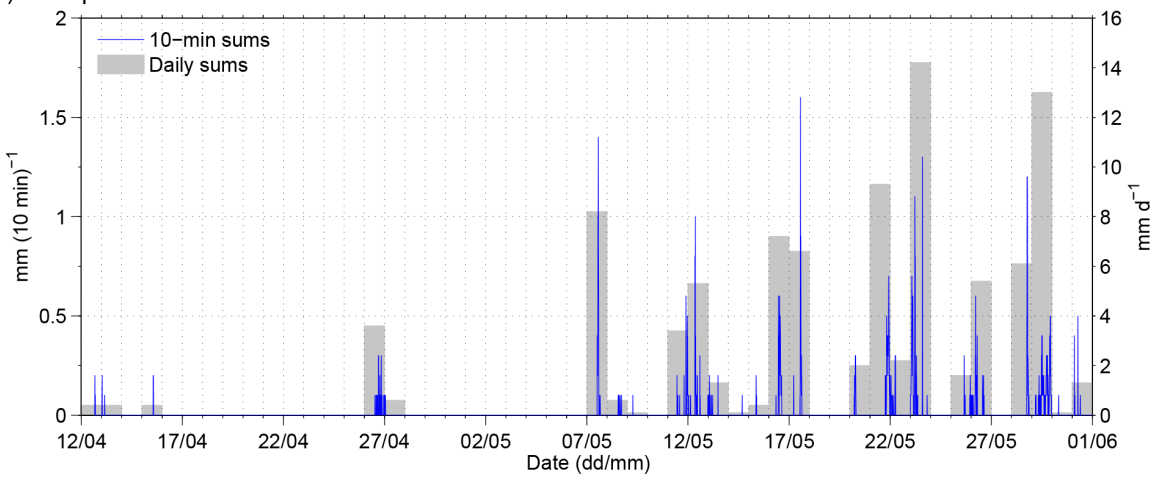

Figure 2. (a) Bowen ratio for all energy balance stations as well as for the weighted-averaged fluxes (weighted with the area fraction of each land-use class), calculated from daily averaged values of surface fluxes for 09:00-15:00 UTC; black arrows denote the selected days; (b) sensible heat fluxes $H_{0}$ as used for calculation of Bowen ratio in (a); (c) precipitation from rain gauge measurements at Wasserwerk.

and HALO (Fig. $3 \mathrm{~b}$ and c). The HYB yielded measurements up to $1500 \mathrm{~m}$ (Fig. 3a), i.e., also above the inversion layer, where the aerosol concentration was much lower. This is presumably due an improved performance of HYB after a refurbishment of the laser transceiver shortly before HOPE. It can also be seen that the $w$ measurements of the WLS7 and WLS200 for the lowest $400 \mathrm{~m}$ are qualitatively consistent with the measurements above (Fig. 3a and b).

For a first analysis of the time series, spectra of energy density $S$ were calculated for $w$ at different heights for the lidars at Hambach (Fig. 4a). Additionally, the spectrum of $w$ measurements by an ultrasonic on a $30 \mathrm{~m}$ tower is given and can be compared with those of WLS7 at the lowest range gate $(60 \mathrm{~m})$. Generally, turbulence spectra are characterized by a peak at a certain frequency or wavelength $\left(f_{p, w}\right.$ or $\lambda_{p, w}$, respectively), which yields the largest spectral contribution to the variance, and by a slope in the inertial subrange ( $f S \propto$ $f^{-2 / 3}$ ). According to Kaimal et al. (1976), $f_{p, w}$ is height dependent for spectra of vertical velocity. This dependency is strongest near the surface and weaker or even disappearing in the CBL.

In the selected example, $f_{p, w}$ is about $3 \times 10^{-3}$ to $5 \times$ $10^{-3} \mathrm{~Hz}$ (i.e., time periods are about $3-6 \mathrm{~min}$, length scales are about $1.5-2.7 \mathrm{~km}$ ) for range gates of $200 \mathrm{~m}$ and higher (Fig. 4a). At the lowest given range gate $(60 \mathrm{~m})$ and for the ultrasonic measurement, maximum variance is shifted towards higher frequencies $\left(10^{-2}\right.$ to $\left.10^{-1} \mathrm{~Hz}\right)$, smaller time periods 
(a) WLS200 and HYB (Wasserwerk)

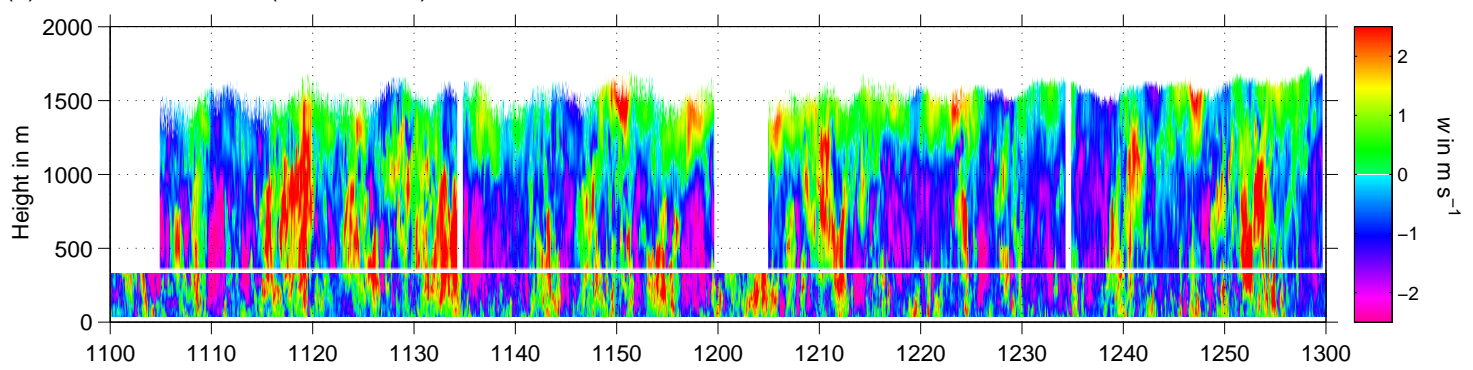

(b) WLS7 and WTX (Hambach)

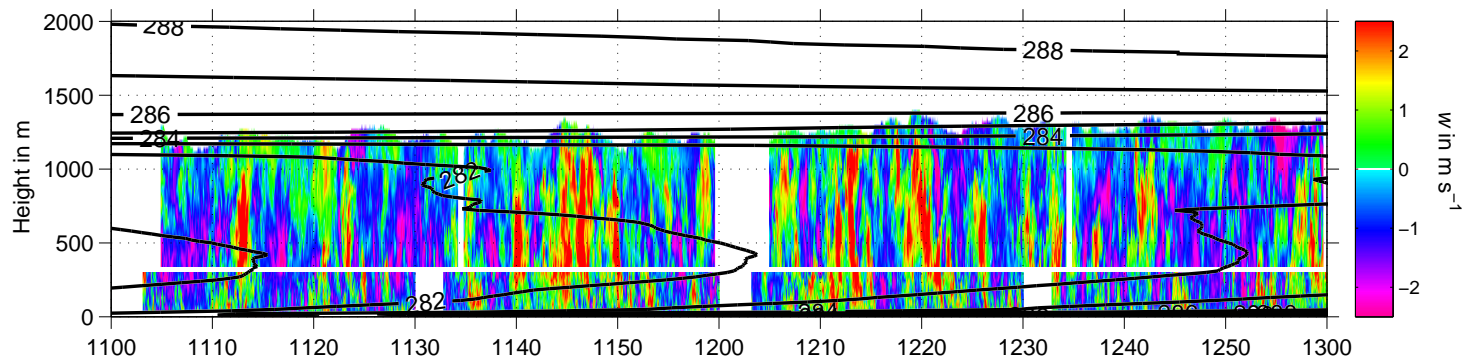

(c) HALO (Selhausen)

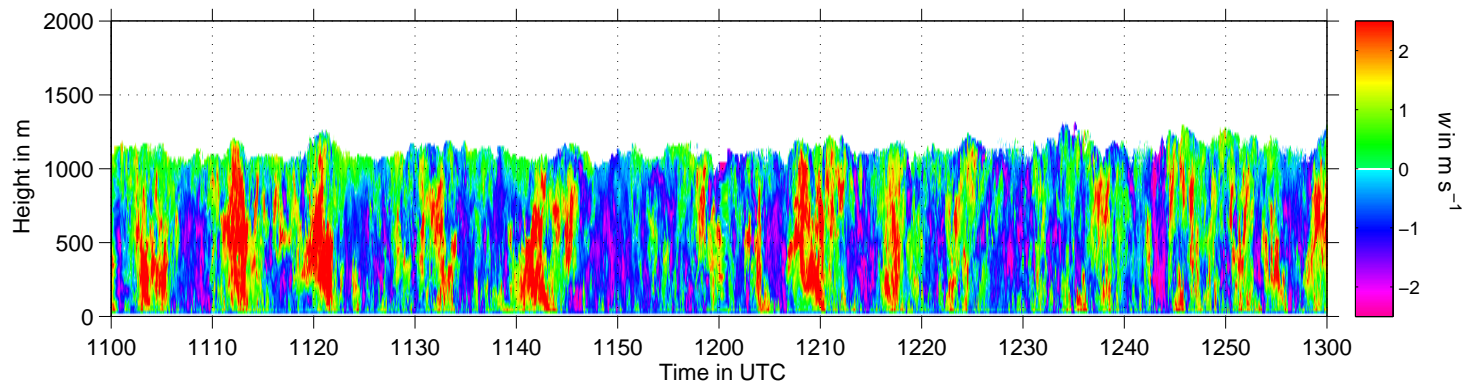

Figure 3. Vertical velocity as observed by Doppler lidars at three different locations on 20 April 2013 (11:00-13:00 UTC) with isolines of potential temperature (in $\mathrm{K}$ ) in (b) as derived from radiosoundings.

(a)

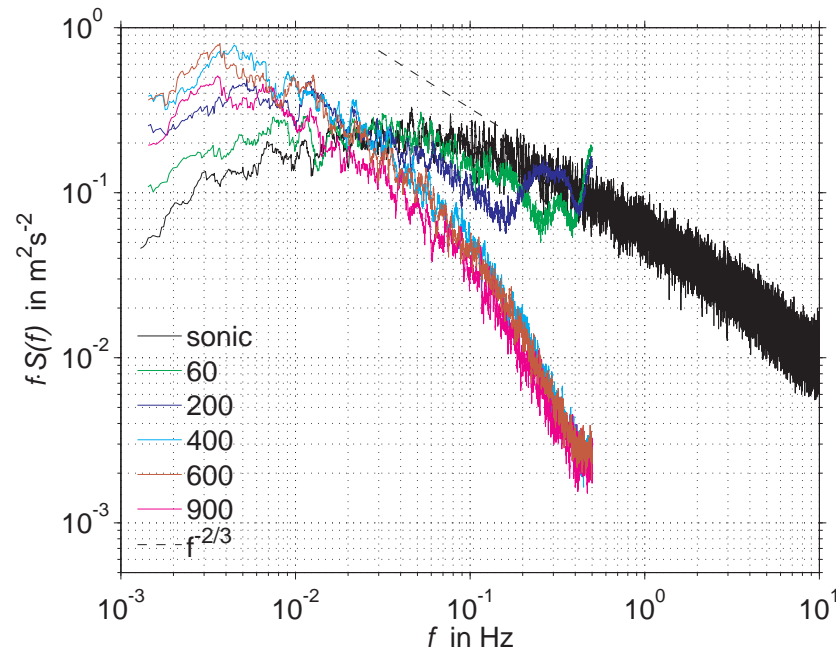

(b)

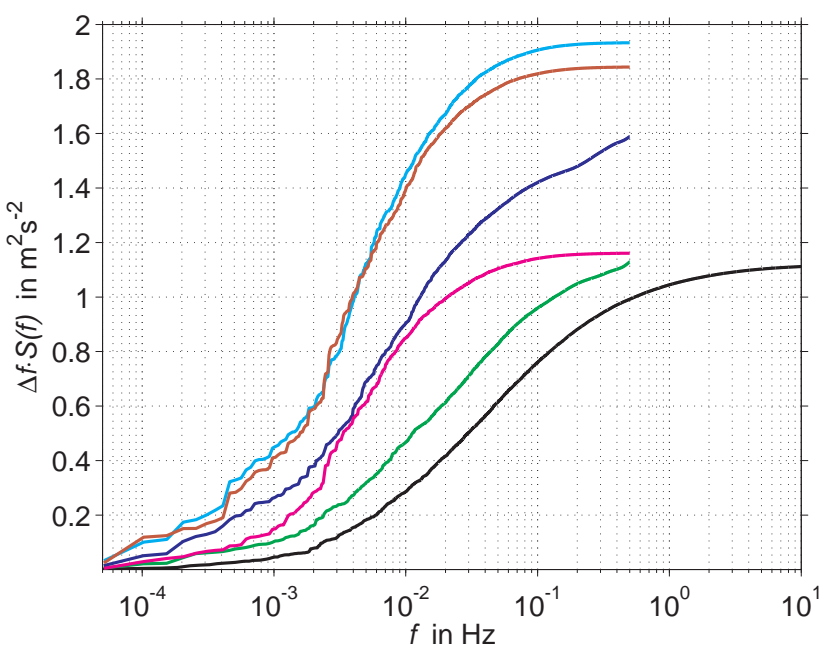

Figure 4. (a) Energy density $(S)$ spectra of $w$ at Hambach on 20 April 2013, 09:00-15:00 UTC, from an ultrasonic at $30 \mathrm{~m}$, WLS7 (60 and $200 \mathrm{~m}$ ), and WTX (400, 600, and $900 \mathrm{~m}$ ); additionally, the theoretical slope in the inertial subrange is given; (b) as in (a), but accumulated curves to illustrate the contributions of different frequencies to the variance. 
(10 s to $2 \mathrm{~min}$ ) and shorter length scales $(80-800 \mathrm{~m}$ ), respectively.

The different values of $f_{p, w}$ in the frequency range of $3 \times 10^{-3}$ to $10^{-1} \mathrm{~Hz}$ are also well visible in the integral spectra (Fig. 4b). As the integral of the spectral energy density over all frequencies is equal to the total variance, the integral spectra also illustrate that vertical motions in this frequency range contribute to more than $50 \%$ of the total variance. Moreover, they indicate that the maximum total variance for the considered time series can be found at $400 \mathrm{~m}$ height.

The inertial subrange can also be discerned in the given spectra, but the slope is steeper than the theoretical one of $-2 / 3$ for the WTX ( $400 \mathrm{~m}$ and above) at frequencies higher than about $0.1 \mathrm{~Hz}$. This effect is also discussed by Frehlich et al. (1998), for example: even if the measurement frequencies of $1 \mathrm{~Hz}$ of the lidar system would be high enough to register fluctuations of frequencies larger than $0.1 \mathrm{~Hz}$, the sampling frequency is restricted due to the spatial averaging of the lidar pulses. The frequency of $0.1 \mathrm{~Hz}$ corresponds to the physical range gate resolution of the instrument $(\Delta r \approx$ $|\boldsymbol{v}| f^{-1}$, with $|\boldsymbol{v}| \approx 8 \mathrm{~m} \mathrm{~s}^{-1}$ on 20 April).

Moreover, Darbieu et al. (2015) also found steeper slopes in spectra derived from aircraft measurements. Lothon et al. (2009) and Darbieu et al. (2015) assume that a steeper slope could also be caused by asymmetric convective structures, i.e., by anisotropy of the $w$ field.

A steeper slope in the inertial subrange also affects the total variance, as can be seen in the integral spectra: the contribution to the total variance increases up to frequencies of $0.1 \mathrm{~Hz}$ only.

Apart from that, the spectra of WLS7 show some artifacts at the highest frequencies, which were also observed by Cañadillas et al. (2011). This is presumably the signature of an aliasing effect, but the reason for this cannot be clarified in detail here, as not all the necessary technical specifications are communicated by the manufacturer.

Based on the spectra, $f_{p, w}$ was estimated for all days. From $f_{p, w}$, the time and length scales $\left(T_{p, w}\right.$ and $\left.\lambda_{p, w}\right)$, on which the turbulent energy contained in the vertical motions is highest, were calculated. They vary for the considered days between 5 and $8 \mathrm{~min}$ or $2-2.7 \mathrm{~km}$, respectively (Table 2 ). The values of $T_{p, w}$ are smaller on days with higher wind speeds, because turbulence elements are advected faster past the location of the measurement. Additionally, scales can be estimated from the autocorrelation function of $w$ in the CBL ( $w$ at $600 \mathrm{~m}$ was chosen here): the autocorrelation becomes negative at a certain time interval and will have a second maximum (and further maxima), if a dominant periodic fluctuation exists. The interval at which the second maximum can be discerned does then correspond to the repetition frequency of the up- or downward motions. This repetition frequency often corresponds to $f_{p, w}$. The values are slightly larger than those estimated from the spectra, but they confirm that $\lambda_{p, w}$ is about $2-3 \mathrm{~km}$ at the three sites on average (Table 2). This means that the energy-containing length scale of the turbulent motions in the CBL was much larger during HOPE than the length scale of the surface heterogeneity, which is several $100 \mathrm{~m}$ at the maximum.

In addition to the calculation via the integrated spectrum, $\overline{w^{\prime 2}}$ was determined directly from the time series. For a validation of both computation methods, the hourly variances for all considered instruments and all 6 days calculated by both methods were compared for the $600 \mathrm{~m}$ range gates and were found to be in good agreement, with a mean relative deviation of $3 \%$.

\subsection{Errors considered for variance calculations}

As in Träumner et al. (2011), the variances were corrected for uncorrelated random noise using a technique proposed by Lenschow et al. (2000). Additionally, the statistical error was considered as described by Lenschow et al. (1994). This method is based on the separation of the random and the systematic error (Appendix A). On days with higher wind speed, the integral time scale and, hence, the statistical error is smaller (Table 2). By this, the dependency of sample size on the mean wind speed is considered implicitly. Even if the signal noise is considered, we cannot be sure that different instruments can provide identical measurements, especially if they are from different manufacturers and are based on different technical principles like HALO and WLS200 compared to the WindTracer systems. Therefore, both WLS200 and HYB were operated at Wasserwerk in the vertical stare mode on 20, 22, and 24 April, so that the $w$ measurements of the two lidar systems could be compared directly. The cross correlation function between the two $w$ time series on 20 April was calculated for measurement heights between $400 \mathrm{~m}$ and $1000 \mathrm{~m}$ (not shown). The highest correlations $(>0.8)$ can be found between 600 and $800 \mathrm{~m}$. As for the autorcorrelation functions, an oscillation between positive and negative values is observed for increasing time lags, symmetrically for positive and negative ones. For 18 and 22 April, the maximum correlations are 0.88 and 0.95 , respectively. This means that the two measurements were not perfectly the same on all days, but sufficiently well correlated to possibly yield similar statistics. The variance differences resulting from different effective range gate lengths as well as single-pulse energies will be taken into account for the spatial comparisons in Sect. 4.3.2.

Finally, another error that may have an influence is the missing variance contribution in the higher frequency part of the spectrum due to the vertical averaging of the lidar measurements. This error will be neglected here, as it would lead to higher variances at all stations and not change the spatial differences. Moreover, the missing contributions are small compared to the absolute values of variance. 


\subsection{Scales and scaling parameters}

According to Lenschow et al. (1980) and Sorbjan (1989), vertical profiles of $\overline{w^{\prime 2}}$ can be normalized and best fitted by

$$
\begin{aligned}
& \overline{\frac{w^{\prime 2}}{w_{*}^{2}}}=1.8\left(\frac{z}{z_{i}}\right)^{2 / 3}\left(1-0.8 \frac{z}{z_{i}}\right)^{2} \text { and } \\
& \overline{w^{\prime 2}}=1.17\left(\frac{z}{z_{i}}\right)^{2 / 3}\left(1-\frac{z}{z_{i}}\right)^{2 / 3},
\end{aligned}
$$

respectively. The convective velocity scale is defined as

$w_{*}=\left(\left.z_{i} \frac{g}{\overline{\theta_{v, 0}}} \overline{w^{\prime} \theta_{v}^{\prime}}\right|_{0}\right)^{1 / 3}$,

with the CBL height $z_{i}$, the gravitational acceleration $g$, the temporal mean of virtual potential temperature at the surface $\overline{\theta_{v, 0}}$, and the kinematic sensible heat flux at the surface, $\left.\overline{w^{\prime} \theta_{v}^{\prime}}\right|_{0}$. For the sensible heat flux, the weighted-averaged heat flux (see Sect. 2.3) as well as the fluxes measured by the energy balance stations next to the lidar instruments can be used here. To distinguish between both scaling approaches of the variance values, they will be called averaged and local scaling, respectively, in the following investigation.

For $z$ axis scaling as well as to calculate $w_{*}$, the CBL height has to be determined. At least, three different methods are in use, depending on the available measurement systems (cf. Emeis et al., 2008; Träumner et al., 2011, and references therein): (1) determining the CBL capping inversion from radiosonde profiles, (2) estimating the top of the aerosol layer from lidar backscatter data, and (3) calculating the top of CBL convection from profiles of the vertical velocity variance. While the first two methods can be regarded as proxies for the CBL depth, the third method is a direct one. Tucker et al. (2009) systematically investigated the determination of the $z_{i}$ using variance profiles and found that a threshold value to which the variance decreases was the best objective criterion. Träumner et al. (2011) determined this threshold value for the HYB for several field campaigns and found that a value of $0.16 \mathrm{~m}^{2} \mathrm{~s}^{-2}$ gave the best results.

For the 6 days investigated here, the methods agree well for most time steps around noon (dashed lines and black dots in Fig. 5). Mainly before 1100 and after 15:00 UTC, method 3 yields lower values of $z_{i}$ than method 2 . The reason is that especially method 2 tends to detect the cap of the residual layer, which is not the case for method 3. However, the threshold value of method 3 is not applicable to all of the profiles here. For several time steps, the decrease of variance with height is weak, and the variance does not reach the defined threshold, so that $z_{i}$ cannot be determined by method 3 . In contrast to method 1, method 2 also provides values for periods when no radiosoundings are available. Therefore, $z_{i}$ values derived by method 2 are used for the following calculations. Correlating all $z_{i}$ values from method 1 with values derived by method 2 from different lidars shows that $z_{i}$ values derived from backscatter data of WTX at Hambach fit best.

The values of $w_{*}$ resulting from using $z_{i}$ determined by method 2 and the weighted-averaged fluxes are also given in Fig. 5 (gray lines). A comparison of diurnal maximum values of $\overline{w^{\prime 2}}$ and $w_{*}$ is included in Table 2. From $w_{*}$, a convective time scale $t_{*}=z_{i} / w_{*}$ can be derived that describes how long it takes to transport an air parcel from the ground to the top of the CBL. Therefore, $t_{*}$ is also known as large-eddy turnover time. Comparing $t_{*}$ and $T$ (Table 2), it is obvious that the large-eddy turnover time is on all days larger than the energycontaining time scale of the turbulence elements, $T$, which depends on their advection past the location of measurement (Sect. 3.1). This means that the turbulence elements do not change substantially during the time it takes them to pass the lidar.

\section{Spatial and temporal differences of vertical velocity variances}

\subsection{Profiles of variance and skewness: examples for 20 April}

Examples of profiles of $w$ variance calculated for four instruments at the three locations are shown in Fig. 6. The given times always indicate the end of the averaging period of $1 \mathrm{~h}$. As described by Deardorff (1974) or Lenschow et al. (1980), the variance profiles display a maximum at a height of about one-third of the convective boundary layer (the top of the CBL is between 1000 and $1400 \mathrm{~m}$ on 20 April, Fig. 5) and a decrease above. The profiles in Fig. 6 are not normalized so that the diurnal evolution can be observed: variances are small at 10:00 UTC (12:00 LT), increase to maximum values at about 12:00-14:00 UTC and decrease subsequently. Above a local minimum indicating the top of the CBL, an increase of variance can be seen in several profiles (e.g. 13:0016:00 UTC profiles of HYB at about $1500 \mathrm{~m}$, Fig. 6a). These higher values lie in and above the capping inversion of the CBL (Fig. 3b) and may be caused by gravity waves in the capping inversion and a stable layer above the CBL.

As already shown by the comparison of vertical velocity measurements of the smaller WLS7 and of WTX (Fig. 3), the combined variance profiles fit well at the transition height from one instrument to the other (Fig. 6d). The maximum variance is sometimes located at low heights that are not covered by HYB or WTX (for example, at 11:00 UTC in Fig. 6c), indicating the usefulness of the combination of different lidar systems with complementary ranges. The variance profiles derived from the measurements of HYB and WLS200 (Fig. 6a and b) do not agree in all details, as indicated by the calculated cross correlations, but the profiles are much more similar to each other than to the profiles from the 

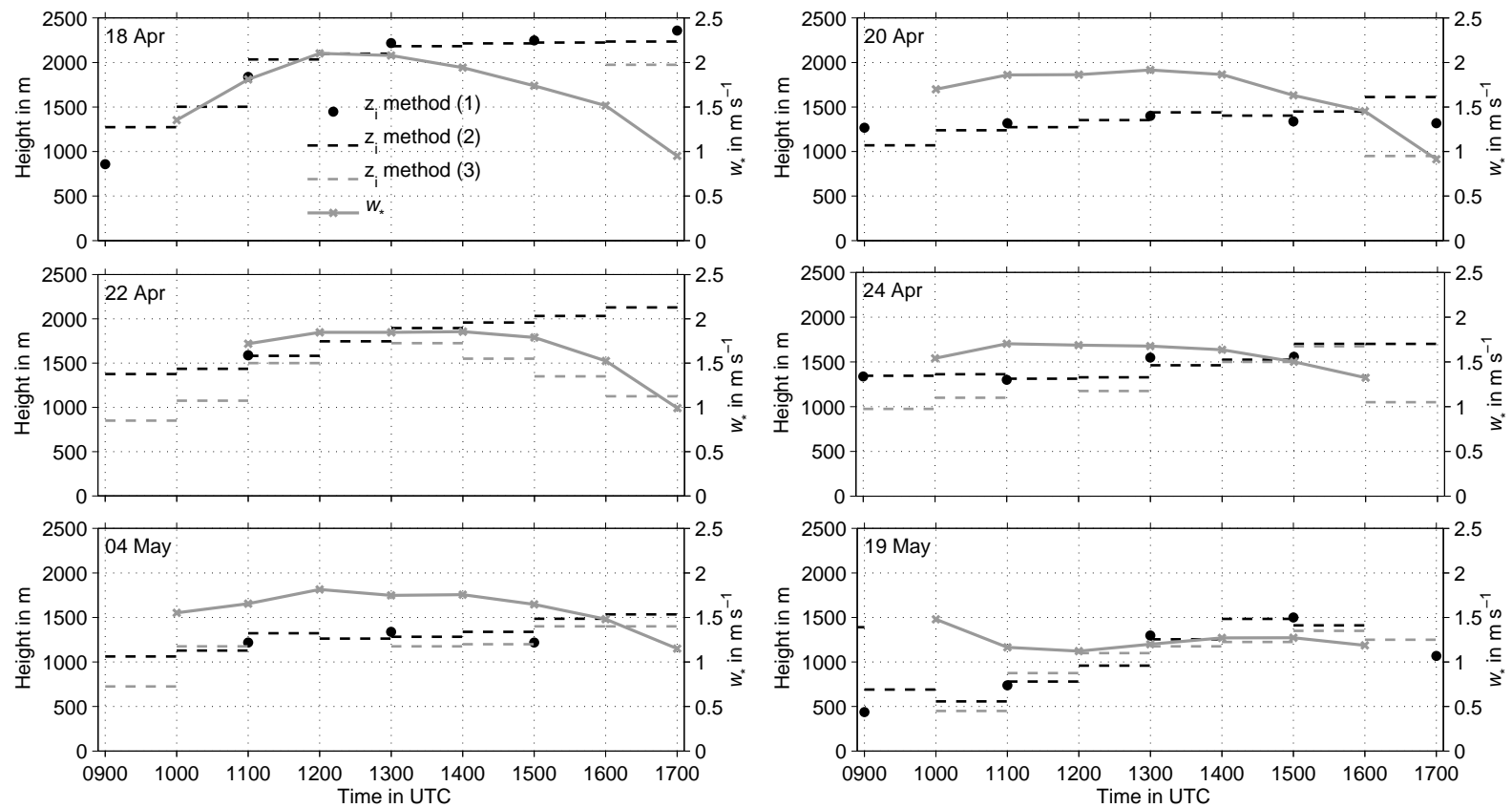

Figure 5. CBL heights derived from radiosoundings (maximum temperature gradient = inversion; method 1), from lidar backscatter data (WTX; method 2) as well as from a variance threshold (method 3) for all considered cloud-free days; additionally, the convective velocity scale $w_{*}$ (determined using weighted-averaged values of sensible heat flux) is given.

(a) Wasserwerk (HYB)

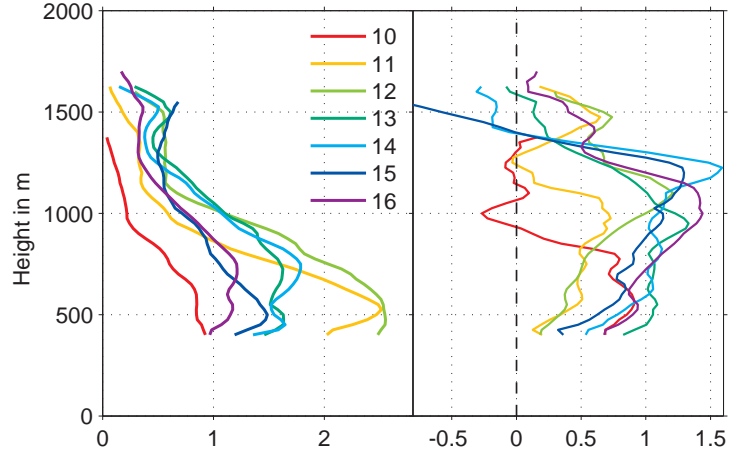

(c) Selhausen (HALO)

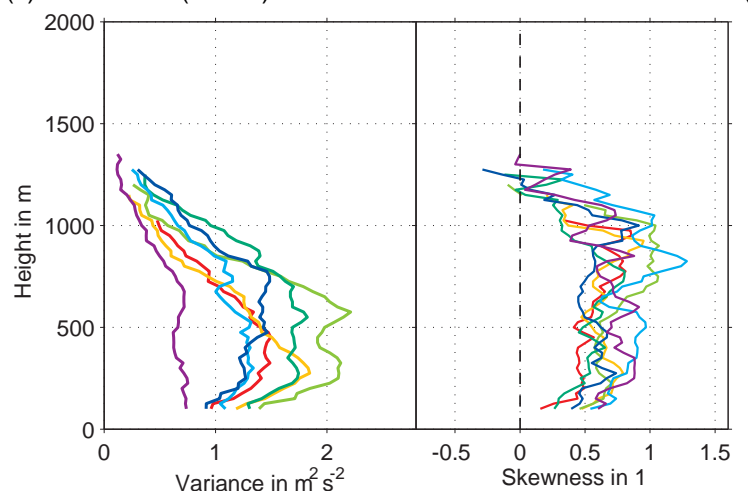

(b) Wasserwerk (WLS200)

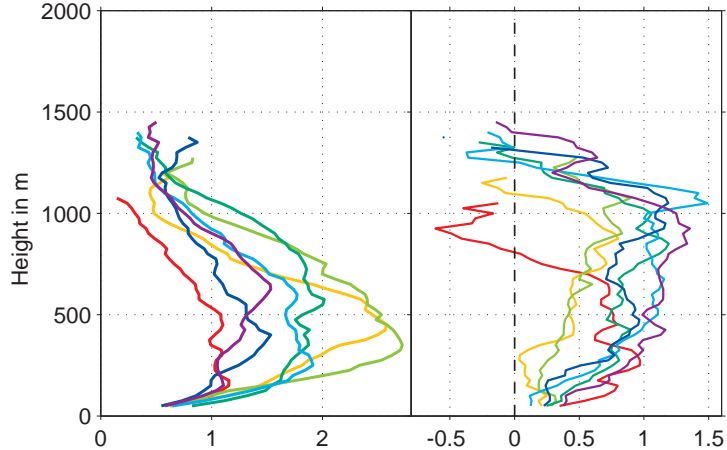

(d) Hambach (WTX)

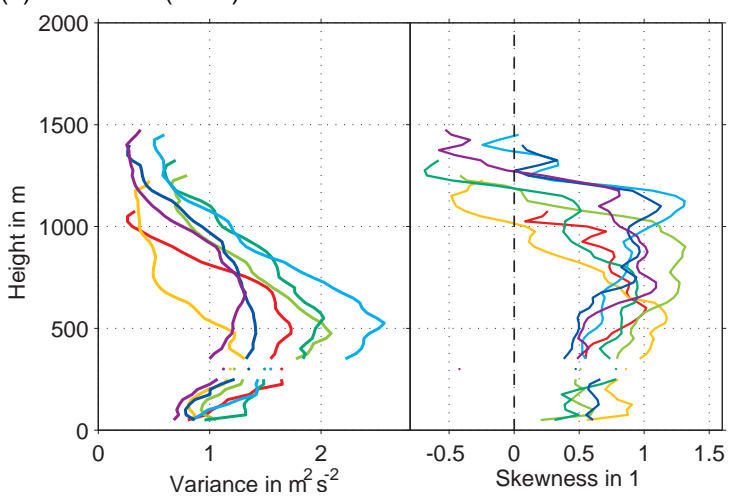

Figure 6. Vertical profiles of hourly vertical velocity variance and skewness from lidar measurements at the three locations for 10:0017:00 UTC on 20 April 2013; the legend labels in (a) refer to the end in UTC for each averaging period of $60 \mathrm{~min}$. 
(a) Hambach
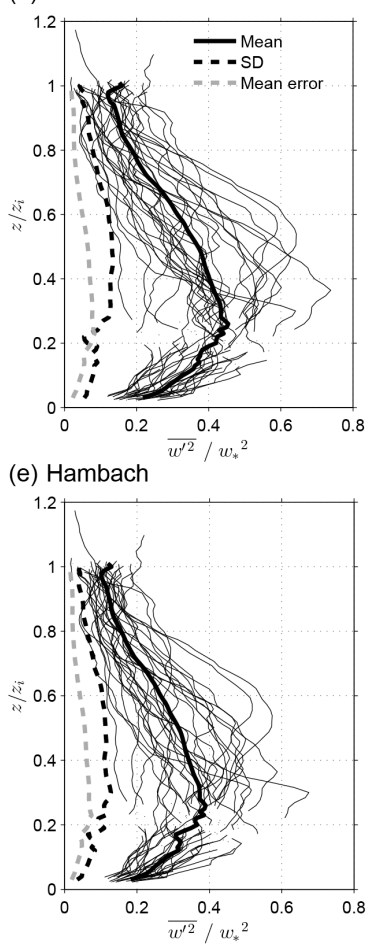

(b) Wasserwerk

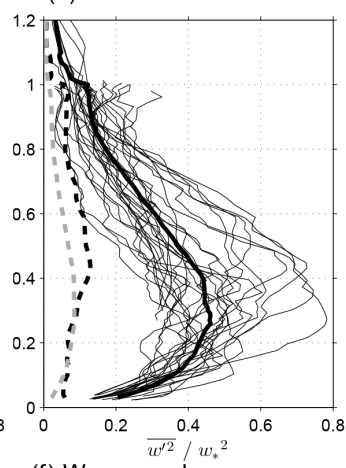

(c) Selhausen

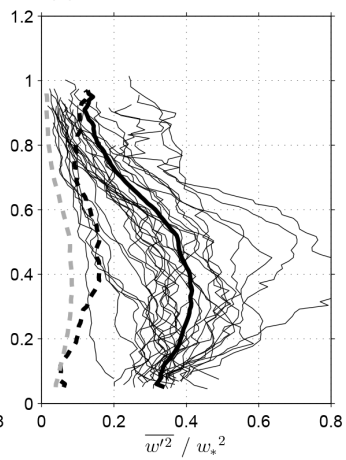

(g) Selhausen (NIE) (d) idealized profiles

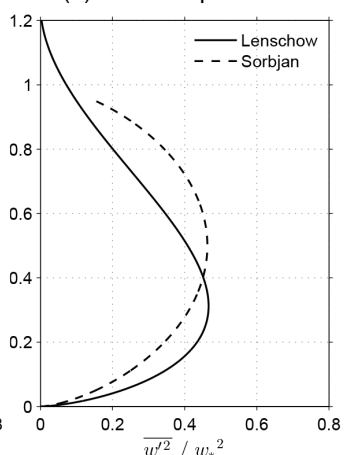

(h) Selhausen (SE1
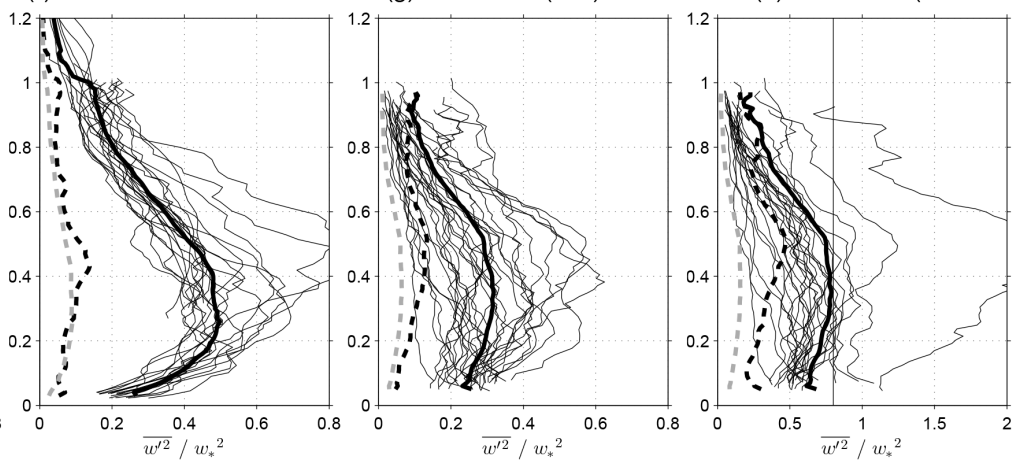

Figure 7. Normalized hourly variance profiles for 18, 20, 22, 24 April and 04 May (11:00-16:00 UTC) with mean profile, standard deviation and mean normalized statistical error (legend in a), using averaged (a, b, c) and local scaling (e, f, $\mathbf{g}, \mathbf{h})$ for each location; different energy balance stations were used for scaling the profiles of Selhausen in $(\mathbf{g}, \mathbf{h})$; in $(\mathbf{d})$, the idealized profiles according to Eq. 1 are given.

other two sites in terms of structure, temporal evolution, and absolute values.

Additionally, profiles of skewness $\left(\overline{w^{\prime 3}} /{\overline{w^{\prime 2}}}^{3 / 2}\right)$ are analyzed (Fig. 6). Positive skewness is usually expected in the $\mathrm{CBL}$ and means strong, narrow updrafts and weaker, broader downdrafts. On 20 April, values of skewness are positive within the CBL. They confirm the existence of a well-mixed boundary layer, as they illustrate a net upward transport of variance (according to the variance budget equation of Stull, 1988) and with this, of turbulent energy. This means that the turbulent energy is mainly created at the surface, i.e., by buoyancy.

\subsection{Scaling of variance profiles}

\subsubsection{Overview of all scaled variance profiles}

Diurnal variability of $w$ variance is obvious on 20 April (Fig. 6). This temporal variability should be eliminated by scaling with $w_{*}$, assuming that the temporal variability of the $w$ variance depends mainly on the strength of buoyancy. It is expected that the scaled profiles are similar within the range of uncertainty indicated by the statistical error. Differences of the Bowen ratio point to a large spatial heterogeneity (Sect. 2.3). Hence, at an individual location, the diurnal cycle of the energy input as well as differences from day to day may be taken into account better by local scaling than by the averaged one (see Sect. 3.3 for the definition of the scaling approaches). Therefore, also the question is addressed whether the spread of the profiles at each individual location is smaller for the locally scaled profiles. On 19 May, which is the only day falling into the wetter period with less surface heterogeneity, lower Bowen ratio and consequently, lower $w_{*}$ is observed at all stations (see Sect. 2.3, Figs. 2 and 5). This day is excluded from the analysis of the scaled profiles.

There were two energy balance stations were located near Selhausen: the energy balance station of Niederzier was about $1 \mathrm{~km}$ north of Selhausen, which may be relatively far away, but the land-use class was the same as at the lidar location. The station called SE1 was closer, but the land-use class there differed and the flux was very low, even lower than at Ruraue (Fig. 2b), which was located in a meadow close to a river. Both are used for local scaling of the variance profiles from Selhausen. As Niederzier is a bare-soil station with relatively high sensible heat fluxes (Fig. 2b), i.e., a high Bowen ratio, and SE1 is characterized by a low Bowen ratio, large differences are found between the two normalizations: the maximum values of mean normalized variance are 0.32 and 0.79 , respectively (Fig. $7 \mathrm{~g}$ and h). For the averaged scaling, by contrast, the maximum value of the mean scaled variance at Selhausen is 0.42 (Fig. 7c), which is closer 
(a) Averaged scaling

(b) Local scaling

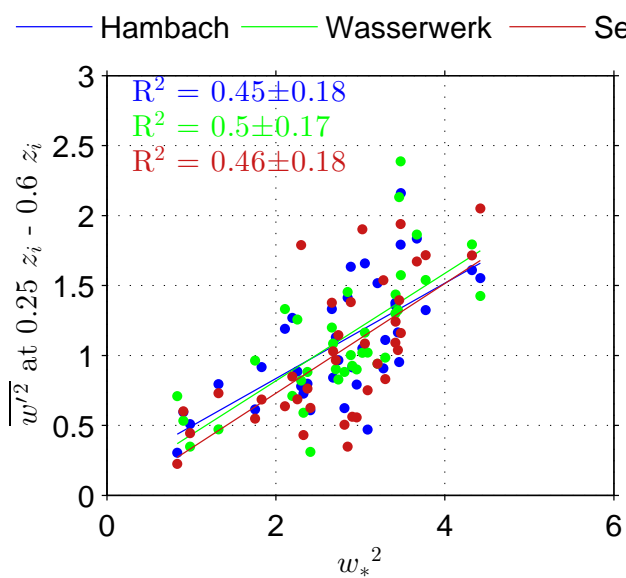
Selhausen (averaged/SE1)—Selhausen (NIE)

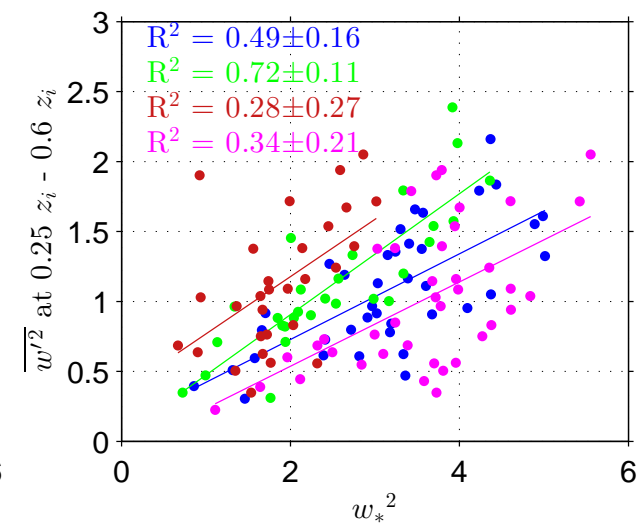

Figure 8. Correlations of vertical velocity variance averaged over 0.25 to $0.60 z_{i}$ and $w_{*}^{2}$, calculated using the weighted-averaged fluxes (a) and fluxes of nearby stations (b) for all time steps as in Fig. 7 but for 10:00-17:00 UTC, with lines of best fit from linear regression, squared correlation coefficients $R^{2}$ and confidence interval at the $95 \%$ level.

to the mean values of $\overline{w^{\prime 2}} / w_{*}^{2}$ at Hambach and Wasserwerk (0.45 and 0.46, respectively, Fig. 7a and b). This means that in comparison to the scaled variances at the other locations, the surface sensible heat flux at Niederzier is too high and SE1 too low with respect to the observed CBL turbulence at Selhausen. The mean variance profiles at all locations display a vertical behavior that is similar to the profile of Lenschow et al. (1980, Fig. 7d), with a maximum in the lower half of the CBL, but not exactly at $0.35 z_{i}$. The difference between standard deviation of all profiles and the mean normalized statistical error signifies their temporal variability which is not explained by variability of buoyancy. At Hambach and Selhausen, the standard deviation is higher than the statistical error at all heights, most distinctly between 0.2 and $0.6 z_{i}$. The mean relative differences between error and standard deviation, vertically averaged, lie between 5 (Fig. 7f) and $36 \%$ (Fig. 7h). At Wasserwerk, the difference is small, especially for local scaling (Fig. 7f). This indicates either that turbulence at Wasserwerk is strongly influenced by nearby surface conditions or that the nearby surface conditions represent the larger-scale upstream conditions very well.

In a similar investigation, Lenschow et al. (2000) found a difference of $10 \%$ between error and standard deviation. They explained it by dependency on wind shear or stability, represented by $-z_{i} / L$. However, a dependency of $w$ variance on $-z_{i} / L$ cannot be found here, neither on friction velocity nor on values of wind shear at the CBL top, as derived from radiosoundings.

\subsubsection{Correlation of variance and convective velocity scale}

In a next step, correlation coefficients are determined between the $w$ variance values averaged between 0.25 and
$0.60 z_{i}\left(\overline{w^{\prime 2}}\right.$ ave $)$ and $w_{*}^{2}$. As in Sect. 4.2.1, values of $w_{*}$ for both averaged (1) and local scaling (2) are applied. By vertical averaging of $w$ variances, the height dependency of the maximum is eliminated. In case 1 , the squared correlation coefficient $R^{2}$ is 0.45 for Hambach and 0.50 for Wasserwerk; in case 2, the correlation is slightly higher than in case 1 for Hambach $\left(R^{2}=0.49\right)$ and considerably higher for Wasserwerk $\left(R^{2}=0.72\right)$. For Selhausen, $R^{2}$ is 0.46 in case 1 and lower in case 2 when using the fluxes from Selhausen or Niederzier ( $R^{2}=0.28$ or 0.34 , respectively). This means that the local scaling is not preferable for Selhausen. For Hambach, local scaling is only slightly better than averaged scaling, but local scaling is clearly better for Wasserwerk. For the given sample sizes, the correlations are all significantly higher than zero when considering a confidence interval on a $95 \%$ level. However, only for Wasserwerk using local scaling, the explained variance (concerning the temporal evolution of $\overline{w^{\prime 2}}$ ave, hereafter called "temporal variance" to avoid ambiguity) is significantly higher than $50 \%$. In contrast, for Selhausen using local scaling with SE1, the explained temporal variance is not significantly higher than $10 \%$, indicating that this scaling is not suitable.

Deardorff (1970b) and Deardorff (1974) showed that $\overline{w^{\prime 2}}\left(0.35 z_{i}\right)=a w_{*}^{2}$ and found values of $a$ between 0.37 and 0.44 , derived from both numerical experiments and different observations. Here, $R^{2}$ is $0.34-0.39$ for the averaged $w_{*}^{2}$ values and $0.30-0.43$ for the local ones, which agrees tolerably well with values found before. For Wasserwerk and the local scaling, $a$ is 0.43 , i.e., at the upper limit of values given in literature.

The implication of the correlations found here is that it is hard to find the specific site in a region with heterogeneous surface fluxes which represents the whole upstream conditions relevant for the turbulence in the CBL. There- 
fore, it is preferable to apply a weighted-averaged flux for scaling. A possible explanation why the correlation for local scaling (Wasserwerk) is higher than for averaged scaling is the uncertainty of the spatial averaging procedure and with this, of averaged scaling, due to the combination of different land-use classes as well as the choice of the considered area (Sect. 2.3).

\subsubsection{Investigation of outliers}

The findings show that temporal variability of $w$ variance cannot be completely eliminated by scaling and that the remaining variability cannot be explained by wind shear or stability. Therefore, individual profiles with particularly high values of $\overline{w^{\prime 2}} / w_{*}^{2}$ are examined in detail. The largest outliers from Wasserwerk, which has the smallest portion of unexplained temporal variance, are selected (Fig. $7 \mathrm{~b}$ and f, respectively). They occur at 12:00 UTC on 20 and 24 April. Each of the two profiles is compared to a profile from the respective day which is more similar to the mean (Fig. 7). Radiosonde profiles indicate no strong diurnal change in wind speed or direction on these two days (not shown). The comparison, including error bars, indicates that $\overline{w^{\prime 2}} / w_{*}^{2}$ is significantly higher for the selected time periods than usual (Fig. 9ai and bi). If longer time periods are chosen, differences decrease, but the statistical error decreases likewise so that they are still significant.

A hypothesis for high values of $\overline{w^{\prime 2}} / w_{*}^{2}$ is the occurrence of more numerous or stronger thermals. Lenschow and Stephens (1980) developed a method for a sub-sampling of thermals from the time series of $w$ and Lenschow and Stephens (1982) showed that the variance of thermals is 22.5 times higher than for the environment, depending on the method of calculation (the ratio is higher when the mean velocity of the sub-samples is subtracted before calculating the variance). As a sub-sampling would be beyond the scope of this investigation, the frequency distributions of the respective time series are investigated (Fig. 9). As variance is equal to the second central moment of a probability distribution, larger variance signifies a broader and flatter distribution by definition. The frequency distribution for 20 April, 11:00-12:00 UTC reveals that there is a higher frequency of $w>1 \mathrm{~m} \mathrm{~s}^{-1}$ than between 14:00-15:00 UTC as well as stronger downdrafts (Fig. 9aiv). When the frequency distribution is considered as a function of height (Fig. 9aii), it can be shown that this behavior can be observed between 200 and $900 \mathrm{~m}$, i.e., distributed over a large part of the CBL $\left(z_{i}\right.$ is between 1300 and $1400 \mathrm{~m}$ on this day). On 24 April, the maximum of $\overline{w^{\prime 2}} / w_{*}^{2}$ at 12:00 UTC is elevated compared to the one at 10:00 UTC (Fig. 9bi), while $z_{i}$ is the same (about $1350 \mathrm{~m}$ ) for both periods. In contrast to 20 April, higher variance is caused by a higher frequency of $w>0.5 \mathrm{~m} \mathrm{~s}^{-1}$ only, not by stronger downdrafts (Fig. 9biv). Moreover, the differences between the frequency distributions occur mainly at heights between 400 and $800 \mathrm{~m}$; i.e., they are vertically more confined to the layer where $\overline{w^{\prime 2}} / w_{*}^{2}$ is actually higher. The integral time scale, which is on average $56 \mathrm{~s}$ on 24 April (Table 2), increases to a distinct maximum of almost $200 \mathrm{~s}$ at $800 \mathrm{~m}$ (not shown), indicating broader thermals at 12:00 UTC (and at 11:00 UTC when the integral time scale is about $120 \mathrm{~s}$ at $600 \mathrm{~m})$ than on average.

Thus, while high values of normalized variance at Wasserwerk for the profile at 15:00 UTC on 20 April are caused by strong up- and downdrafts, they are actually caused by broader thermals on 24 April. This agrees with the results of Lenschow and Stephens (1982) that the variance of thermals is higher. However, it is not possible to explain these thermals by corresponding higher surface sensible heat fluxes and, thus, why $\overline{w^{\prime 2}} / w_{*}^{2}$ is higher than on average.

Due to the elevated maximum, the profile for 12:00 UTC on 24 April corresponds better to the symmetrical profile of Sorbjan (1989, Fig. 7d). Caughey and Palmer (1979), e.g., also discuss the variability of heights of the variance maxima reported by different authors. The height-dependent frequency distribution shown here suggests that the elevated maximum is caused by strong thermals rising up to a certain height. LES of van Heerwaarden et al. (2014) also support the finding that an elevated maximum of variance is related to particularly strong plumes.

\subsection{Spatial differences of vertical velocity variances}

The main finding of the investigation of scaled profiles is that averaged scaling was preferable, i.e., that the same scaling could be used for the three locations. This implies that also the absolute values of variance should be similar at the three locations. However, unexplained temporal variance is found even for the "best" scaling. The question is now if there is also a spatial variability of $w$ variance.

One noticeable difference between the hourly variance profiles at the three locations on 20 April (Fig. 6) is the diurnal cycle: While maximum variance occurs at 12:00 UTC at Wasserwerk and Selhausen, it occurs at 14:00 UTC at Hambach. To investigate this spatial difference, the height of maximum variance, $z_{\max }$, is determined for all days and all hourly variance profiles. It is encountered between $0.1 z_{i}$ and $0.5 z_{i}$. A maximum variance $\overline{w^{\prime 2}}$ max is then calculated by vertical averaging of each profile over a height range of $z_{\max } \pm 250 \mathrm{~m}$. The statistical errors are determined for the same height range. The time series of $\overline{w^{\prime 2}}$ max for the three locations are shown in Fig. 10. The difference of $\overline{w^{\prime 2}}$ max between Wasserwerk and Hambach on 20 April for the 12:00 UTC period is not significant when considering the statistical error, but it is significant for the 14:00 UTC period. For other time periods, as for example for 11:00, 15:00, and 16:00 UTC on 18 April, 11:00 and 12:00 UTC on 24 April, significant differences between the individual locations are 
ai) 20 April, Wasserwerk

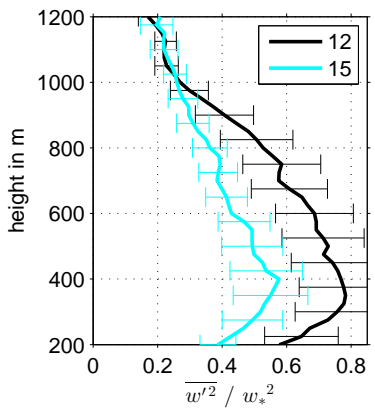

bi) 24 April, Wasserwerk

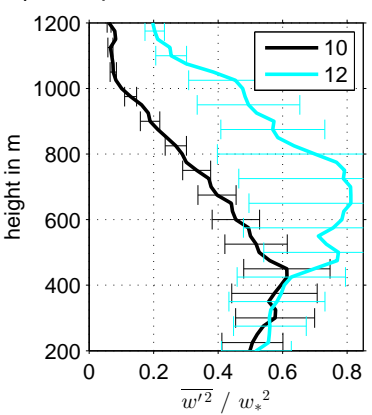

aii) 12 UTC

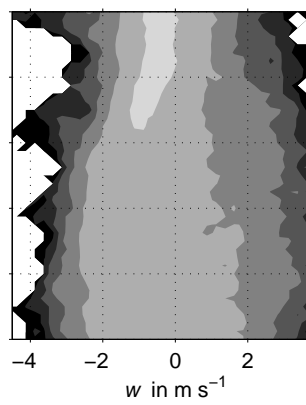

bii) 10 UTC

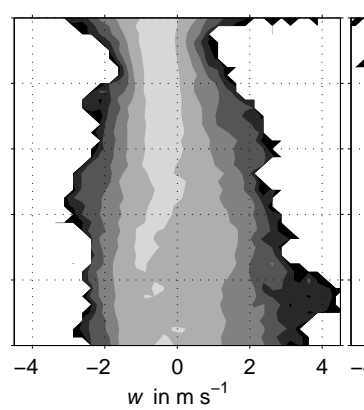

aiii) 15 UTC

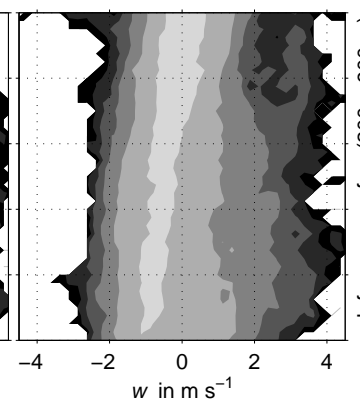

biii) 12 UTC

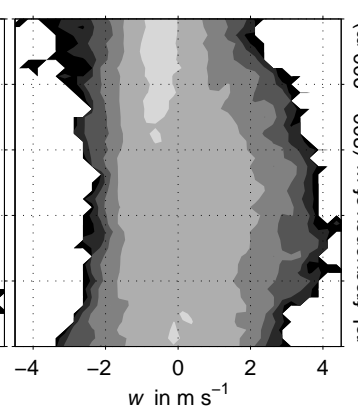

aiv)

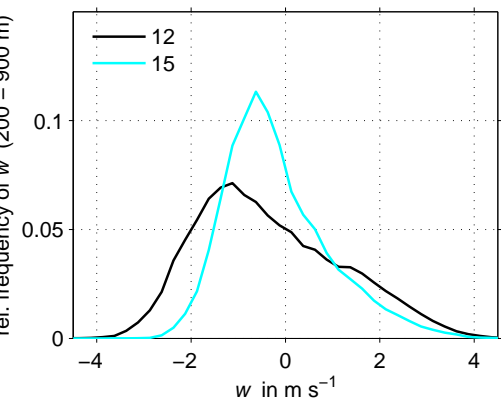

biv)

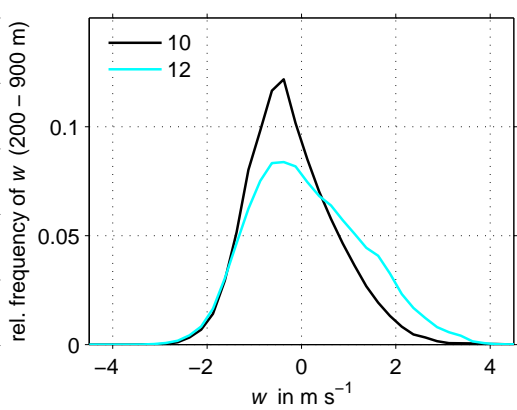

Figure 9. Normalized variance profiles with error bars (statistical error according to Lenschow et al., 1994); for each (ai) and (bi), two time steps were selected from Fig. 7b and f, respectively; for each time step, frequency distributions are given as a function of height (aii, aiii, bii, and biii, gray shading with steps proportional to logarithm of relative frequency, higher values for lighter shadings) and as distributions over a range of heights (aiv, biv).
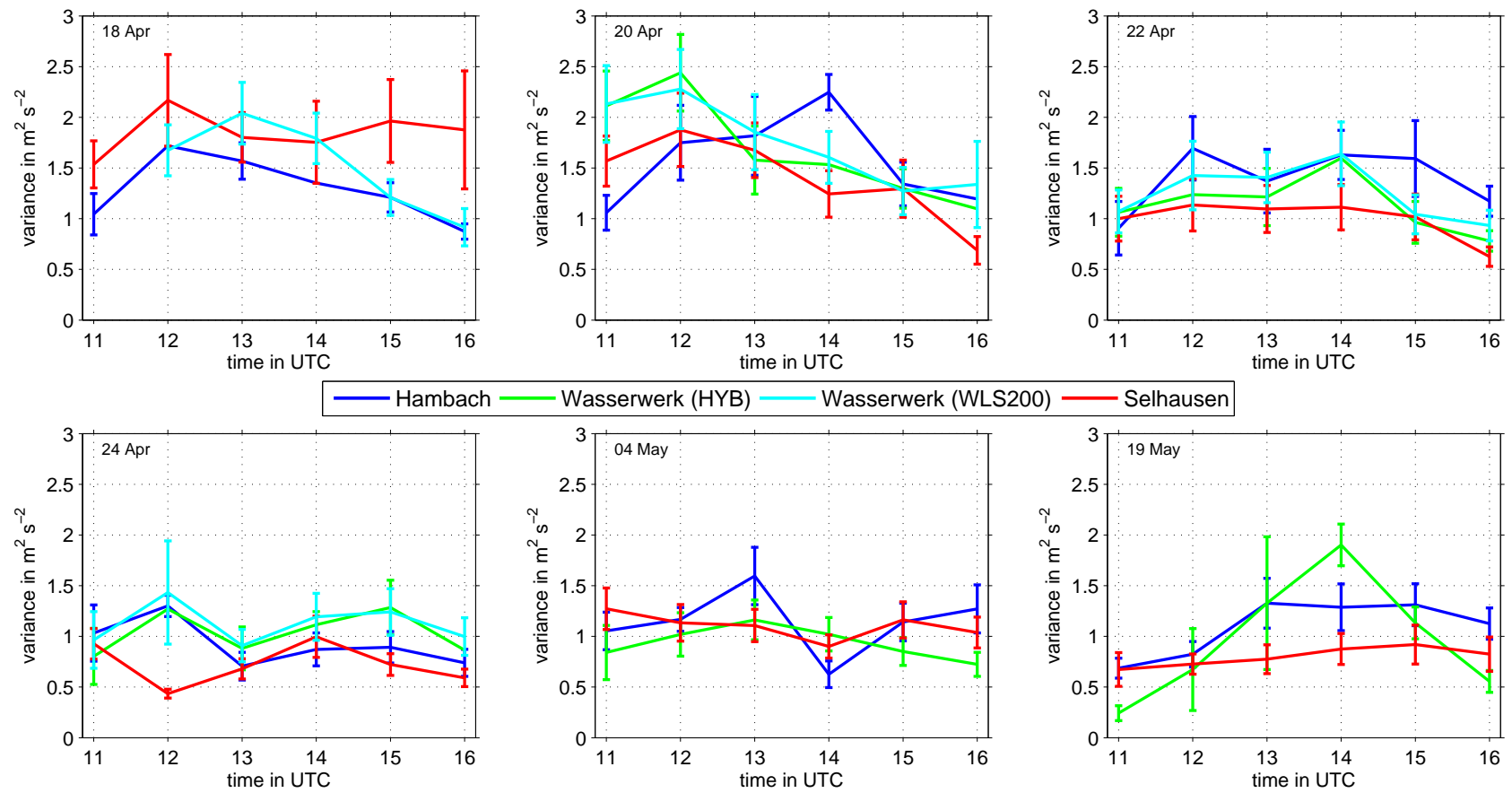

Figure 10. Vertical velocity variances (hourly profiles averaged over $z_{\max } \pm 250 \mathrm{~m}$ ) at the three locations with error bars displaying the statistical error according to Lenschow et al. (1994) for all 6 days (different panels).

also evident. In the following sections, different reasons that could cause significant differences are explored. 
a) 18 April, 15 UTC

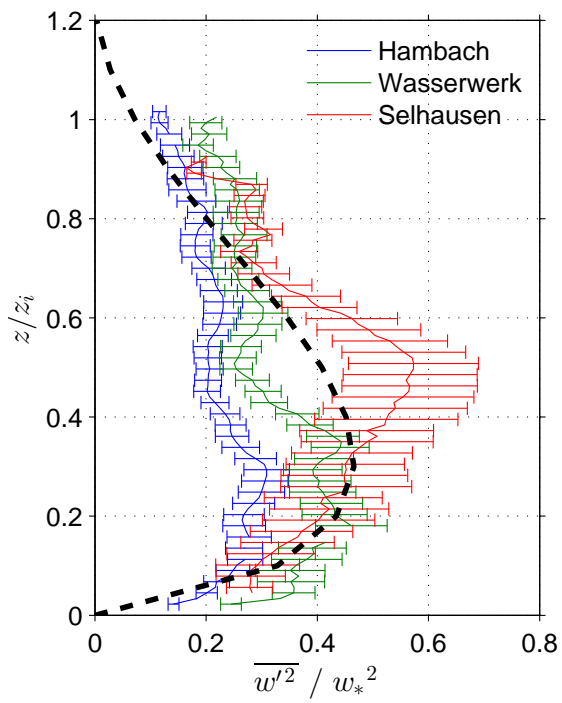

b) 20 April, 14 UTC

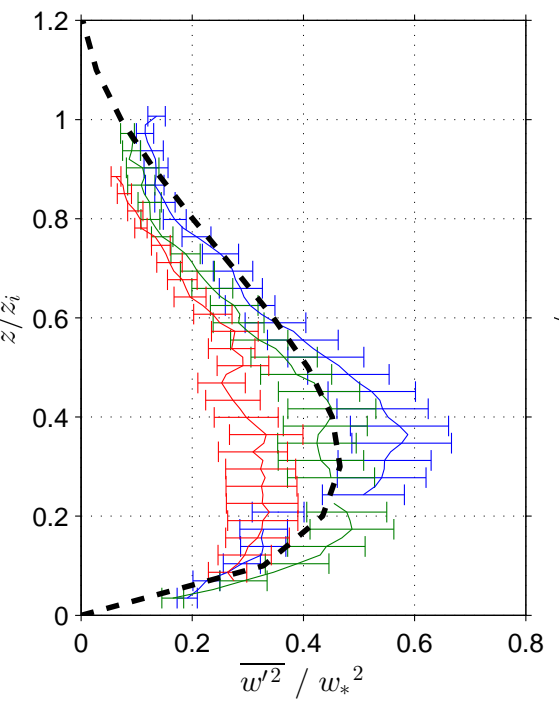

c) 24 April, 12 UTC

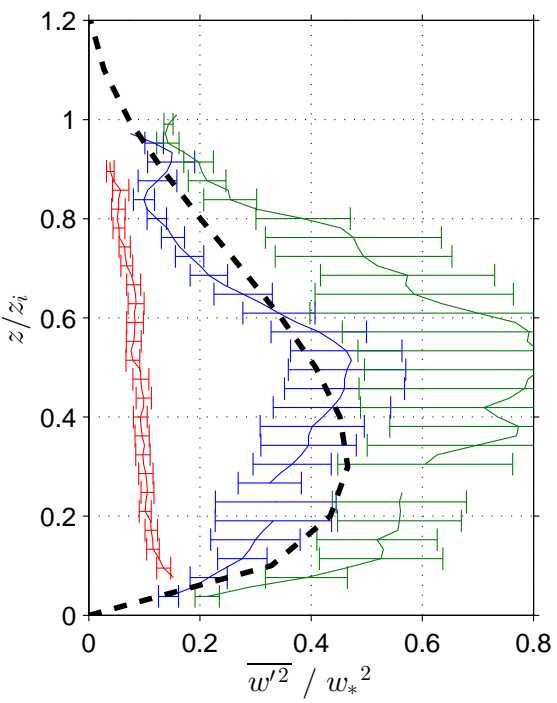

Figure 11. Normalized variance profiles with error bars (statistical error according to Lenschow et al., 1994) for three time periods (local scaling); the black dashed line corresponds to the fit of Lenschow et al. (1980), Eq. (1).

\subsubsection{Influence of the surface energy balance}

For the days investigated here, positive values of skewness confirm that the strength of CBL turbulence is dominated by surface-based buoyancy-driven convection (exemplarily shown for 20 April in Fig. 6). Therefore, it is investigated now whether the detected spatial differences of $w$ variance are related to the spatial heterogeneity at the land surface which was described in Sect. 2.3. Even if local scaling could not eliminate spatial differences on average, it could reduce them for the time periods with significant spatial differences.

Generally, surface heterogeneity as observed during the drier period (Fig. 2) may be caused by heterogeneous surface characteristics such as land use and soil moisture, which influence the partitioning of available energy into sensible and latent heat. On the other hand, heterogeneity also can result from the available energy itself, which can be modified strongly by the occurrence of clouds. As shown in Sect. 2.2, clouds actually influenced incoming radiation on 2 of the 6 selected days.

The spatial heterogeneity of the buoyancy flux at the surface, including the influence of spatially heterogeneous cloud cover, may be considered by scaling the variance profiles with $w_{*}^{2}$ (local scaling). For Selhausen, Niederzier is chosen as it provides better correlations than SE1 (Fig. 8).

For the three selected time periods on 18, 20, and 24 April when spatial differences were observed, scaled profiles with the corresponding error bars are given in Fig. 11. As the statistical error depends on the variance itself (Appendix Eqs. A2 and A3), it is higher for higher variances. The different scaling values for the three locations amplify this effect.
For all time periods, at least two profiles still show statistically significant differences after applying the local scaling. For 18 April, 15:00 UTC (Fig. 11a), the difference between Hambach and Wasserwerk becomes even stronger than without scaling. This means that the spatial differences cannot be explained by the surface heterogeneity. The reason becomes obvious when looking at the net radiation and surface sensible heat flux for the three selected time periods (Fig. 12):

On 18 April at 15:00 UTC, the $w$ variance is the highest at Selhausen and lower at Hambach as well as at Wasserwerk (Fig. 10). If local sensible heat fluxes were responsible for the spatial differences of CBL turbulence between 14:00-15:00 UTC, the spatial flux differences would be similar. However, the flux is highest at Hambach (Fig. 12) so that the scaled variance was the lowest. At Niederzier, the flux is slightly lower and much lower at Wasserwerk. Consequently, the differences of the sensible heat flux cannot explain the variance differences. Moreover, net radiation (Fig. 12) shows that some clouds occurred on this day and from cloud camera images, it is known that also boundary-layer clouds were present between 13:00 and 15:00 UTC. These clouds do not cause considerable temporal variation in the sensible heat flux data, but they can certainly influence the variance profiles (e.g. Neggers et al., 2003).

On 20 April, 14:00 UTC, the variance is highest at Hambach and lower at Wasserwerk and Selhausen (Fig. 10). However, the surface sensible heat flux is equally high at the three locations (Fig. 12). At the same time, the net radiation shows little spatial variability $\left(<20 \mathrm{~W} \mathrm{~m}^{-2}\right)$. Thus, the surface forcing does not display large differences between the three locations, which explains why a scaling using the fluxes from 

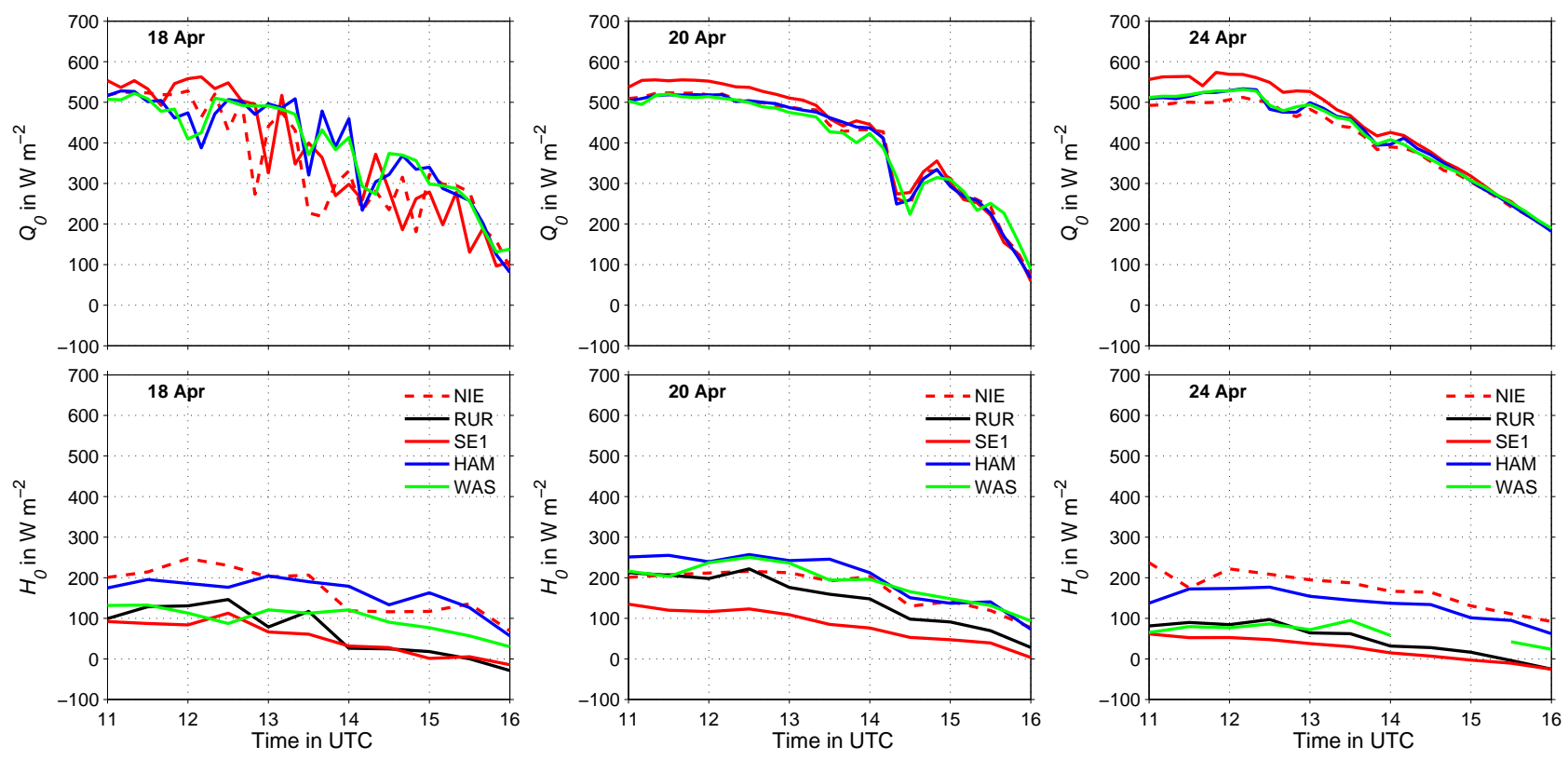

Figure 12. Net radiation ( $Q_{0}$, upper row) and surface sensible heat flux $\left(H_{0}\right)$ at the five energy balance stations (NIE - Niederzier; RUR - Ruraue; SE1 - Selhausen; HAM - Hambach; WAS - Wasserwerk; cf. Fig. 1) for 3 days with significant spatial differences of vertical velocity variances.

the nearby stations does not remove the spatial differences of variances (Fig. 11b).

On 24 April, 12:00 UTC, the variance at Selhausen is significantly lower than at Hambach and Wasserwerk (Fig. 10) but again, the spatial differences between the fluxes cannot explain this difference (Fig. 12). The flux is highest at Niederzier so that the scaled variance profile for Selhausen becomes very low compared to the scaled profiles at the other two locations (Fig. 11c).

Therefore, it must be concluded that the heterogeneous surface conditions cannot explain the statistically significant spatial differences of the $w$ variances. This is consistent with the finding from Sect. 4.2.3 that significantly increased values of the $w$ variance within the diurnal cycle cannot be eliminated by scaling, either.

\subsubsection{Influence of averaging periods and measurement uncertainties}

The variance profiles considered so far were determined using hourly averaging periods. We now want to investigate how strongly the spatial differences are dependent on the length of the applied averaging periods. For this reason, the differences between $\overline{w^{\prime 2}}$ max values at different locations are calculated for different averaging periods $\Delta t$. For the computation of variances for $\Delta t>1 \mathrm{~h}$, the non-stationarity of the CBL, especially due to increasing $z_{i}$ in the morning, has to be considered. For this, $\overline{w^{\prime 2}}$ max values are first determined for the hourly averaging periods and then averaged to re- trieve $\overline{w^{\prime 2}}$ max for longer averaging periods. In contrast, the statistical error (Fig. 13b) is taken from variance calculations for explicitly larger time periods. After that, relative deviations (absolute difference normalized by the mean value) are calculated for each time step and each instrument combination. The resulting mean relative differences are given as an average of all considered 6 days (Fig. 13a). For the 3 days when simultaneous $w$ measurements by HYB and WLS200 at Wasserwerk are available (20, 22, and 24 April), the relative difference between these two measurements at the same site is calculated as well. This gives a good estimate for the uncertainty that exists due to the comparison of measurements by instruments that are based on different technologies or made by different manufacturers (instrument uncertainty).

The daily mean relative deviation for HYB and WLS200 is less than 0.1 for $\Delta t=1 \mathrm{~h}$ and about 0.05 for longer averaging periods. For the other instrument combinations, it is about 0.5 for $\Delta t=10 \mathrm{~min}$ and decreases to about 0.2 for $\Delta t=3 \mathrm{~h}$. For $\Delta t>3 \mathrm{~h}$, it does not clearly decrease further. The mean normalized statistical error for $\Delta t=3 \mathrm{~h}$ is about 0.1 (Fig. 13b), so that the relative deviation is about twice the error. This means that the spatial differences between the variances are not statistically significant on average, at least if the instrument-to-instrument uncertainty is considered. However, this does not exclude the possibility of individual periods with significant spatial differences existing; the diurnal time series of $\overline{w^{\prime 2}}$ max with the corresponding error bars are also compared for larger $\Delta t$ and the significant differences for the periods concerned remain (not shown). At the same 
(a) Relative deviations, average of all days

(b) Average error

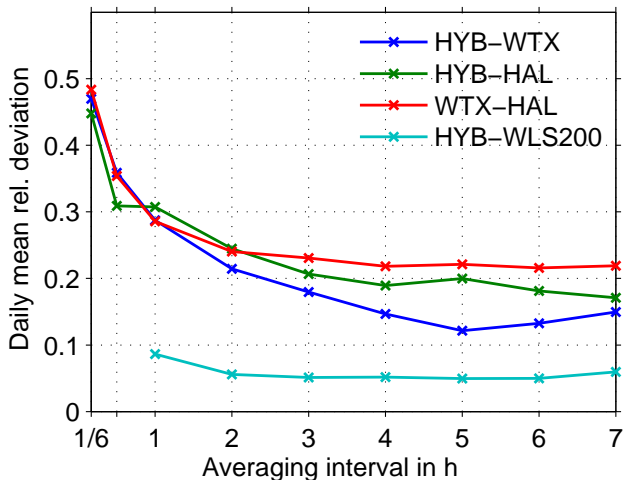

(c) Absolute values for $3 \mathrm{~h}$ interval

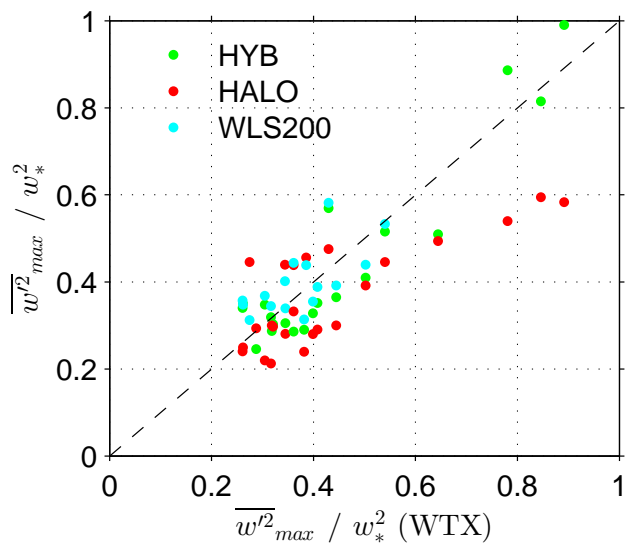

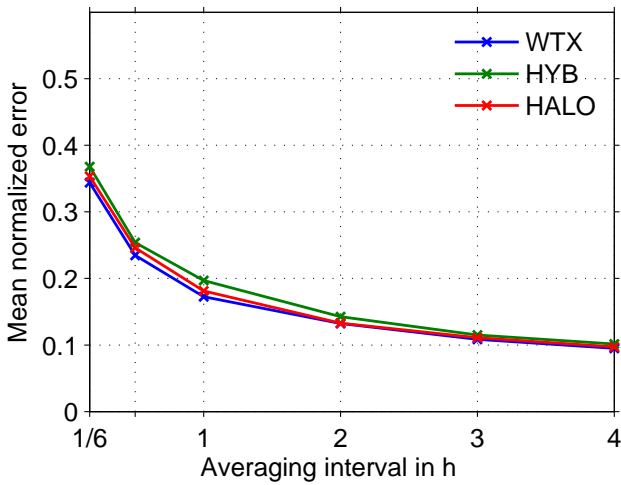

(d) Normalized deviations, $3 \mathrm{~h}$ interval

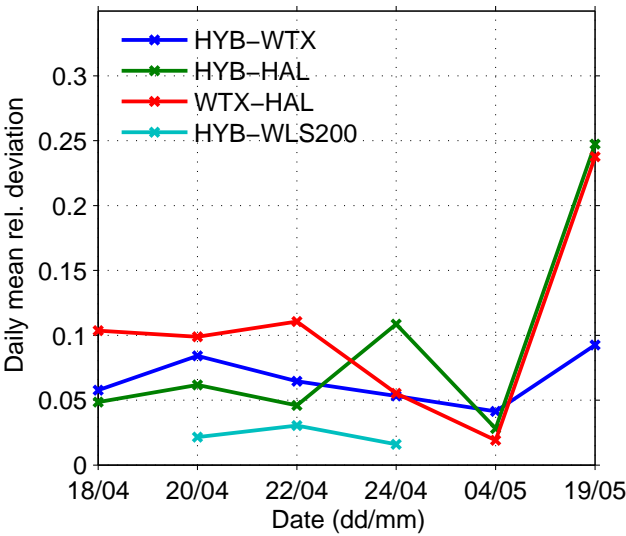

Figure 13. Relative deviations between $\overline{w^{\prime 2}}$ max time series of each two lidars, averaged daily and over all days (a) and statistical error for each instrument, normalized with the respective $\overline{w^{\prime 2}}$ max time series (b), given as a function of the averaging interval used for the calculation of the variance profiles; absolute values of $\overline{w^{\prime 2}}$ max $/ w_{*}^{2}$ for the 3-h averaging interval for HYB, HALO, and WLS200 as a function of $\overline{w^{\prime 2}}$ max $/ w_{*}^{2}$ for WTX (c); deviation normalized with $w_{*}^{2}$ for 3 -h averaging interval for each day (d).

time, a mean relative deviation of about 0.2 for $\Delta t=3 \mathrm{~h}$ means that the mean error that has to be expected when calculating variances from point measurements is about $10 \%$ minus the instrument uncertainty of about $2 \%$ (a factor of 0.5 is taken into account to derive the uncertainty of a single instrument from the calculated deviation); in other words, a point measurement is - on average - spatially representative with an uncertainty of less than $10 \%$ when a measurement period of $3 \mathrm{~h}$ is covered. This agrees with the statistical error of Lenschow et al. (1994) that was derived by theoretical considerations.

As the absolute difference does not provide any evidence of possible biases between the instrument measurements, absolute values of $\overline{w^{\prime 2}}$ max $/ w_{*}^{2}$ are compared in Fig. 13c. The variances are normalized by $w_{*}^{2}$ (averaged scaling) to retrieve comparable values for the different days. While on average they are as high at Wasserwerk (HYB and WLS200) as at Hambach, most values are below the 1-1 diagonal for HALO. This explains why the relative difference is higher between HALO and both other instruments than between HYB and
WTX (Fig. 13a). Nevertheless, there is no clear explanation why the variance is systematically smaller at Selhausen than $3 \mathrm{~km}$ north of this location. The sensible heat flux of SE1 is quite low most of the time, but as shown in Sect. 4.3.1, it is not representative of the surroundings of the HALO site. Finally, to compare the daily differences, the absolute differences between the lidars are normalized by $w_{*}^{2}$ (Fig. 13d).

The comparison reveals that on 3 days $(18,20$, and 22 April), the deviations are largest between HALO and WTX and on 1 day between HALO and HYB (24 April). On 4 May, which is closest to a perfectly cloud-free day, the differences are smallest and on 19 May, which is a day with several mid-level clouds, they are largest. 19 May is the only day that falls into the wetter period with the Bowen ratio being low for all stations. Therefore, scaling with $w_{*}^{2}$ (using a small sensible heat flux) results in higher values than for the other days. The variation of the differences from day to day can, hence, partly be explained by the occurrence of clouds and by the resulting differences of the incoming radiation (Table 2). 
(a) 18 April
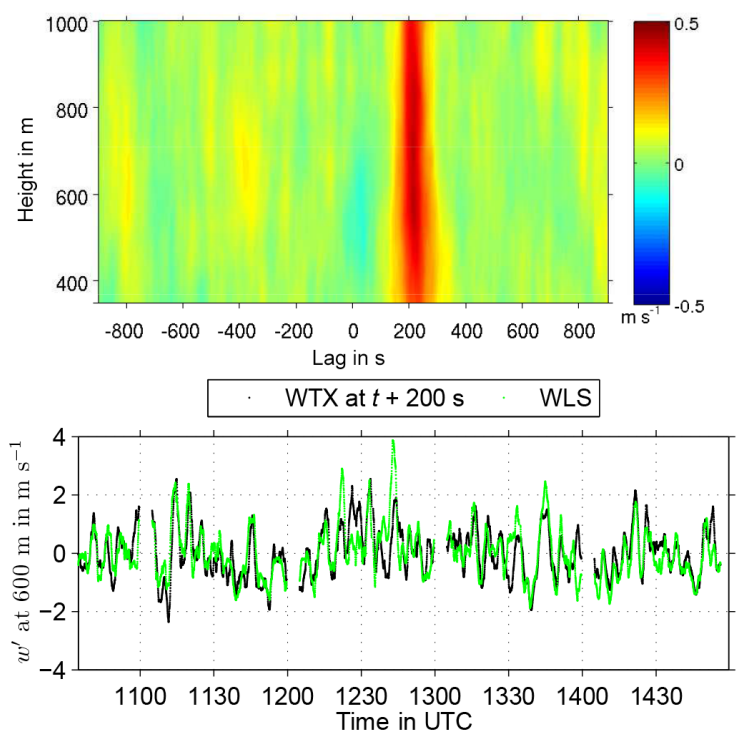

(b) 24 April
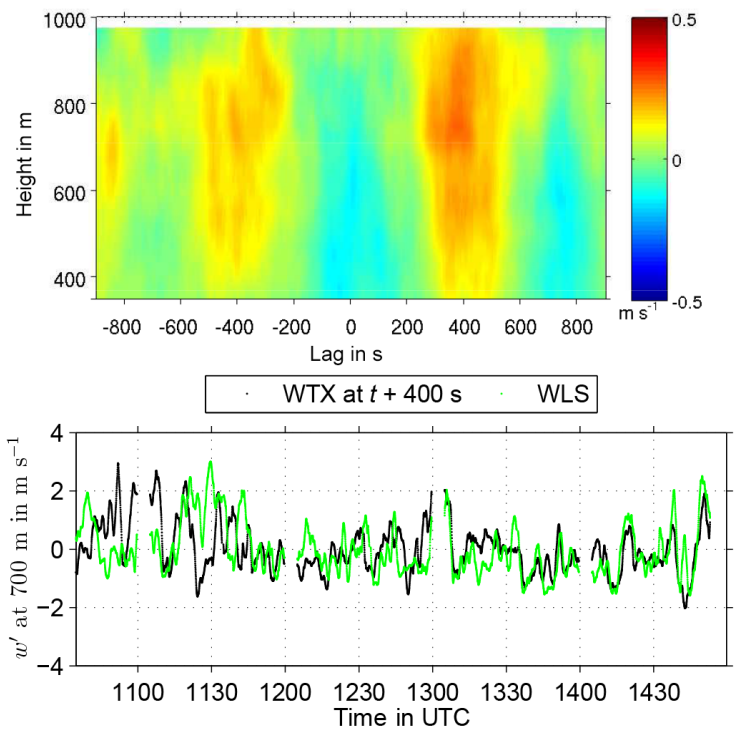

Figure 14. Cross correlation functions between $w^{\prime}$ time series (10:30-15:00 UTC) at Hambach and Wasserwerk (WTX and WLS200, respectively) for all range gates between 380 and $1000 \mathrm{~m}$ (upper row) and $w^{\prime}$ time series ( \pm 50 -s running average) for both lidars at one range gate (lower row) on 18 April (a) and 24 April 2013 (b).

We finally conclude that the spatial differences on average are as large as the statistical error derived from theory, independent of the averaging period. The instrument uncertainty can be estimated to about $2 \%$ and the mean error is about $10 \%$ for an averaging period of $3 \mathrm{~h}$.

\subsubsection{Correlations of vertical velocity at different locations}

For two of the three time periods investigated in Sect. 4.3.1 (on 18 and 24 April), the mean wind direction is west to southwest. On both days, it is noticeable that the diurnal time series of $\overline{w^{\prime 2}}$ max at Wasserwerk and Hambach are very similar, while the time series is different at Selhausen (Fig. 10). As the variances are similar, it can be expected that also the time series of $w$ at Wasserwerk and Hambach exhibit a certain similarity. To investigate this, the cross correlation function of the two time series of $w$ is determined (Fig. 14).

As the convective time scale $t_{*}$ is of the order of $10 \mathrm{~min}$ and the travel time for the given distances between the lidar locations of about $3 \mathrm{~km}$ is between 4 and 12 min, convective cells can be preserved between two locations at least on days with relatively strong mean wind. The day with the highest mean wind speed is 18 April; in the westerly flow, the WTX at Hambach is located downstream of WLS200 at Wasserwerk. The cross correlation function between WLS200 and WTX in fact reveals a distinct maximum of correlation at a time lag of $200 \mathrm{~s}$ (Fig. 14a). The maximum correlation of 0.44 is found at heights between 500 and $900 \mathrm{~m}$. When shifting the time series of $w^{\prime}$ at $600 \mathrm{~m}$ for WTX backwards by $200 \mathrm{~s} \mathrm{com-}$ pared to that of WLS200, the two time series agree very well (Fig. 14a). That means that the larger convective cells are advected from Wasserwerk to the Hambach site without substantial changing (Taylor's hypothesis), which explains the similarity of the time series at the two locations for both $w$ and $\overline{w^{\prime 2}}$ max.

On 24 April, the mean wind direction again is southwest, but weaker than on 18 April. A maximum of the cross correlation function between WLS200 and WTX can also be discerned (Fig. 14b), but it is only 0.27 . Nevertheless, the two time series (WTX shifted by $400 \mathrm{~s}$ ) at $700 \mathrm{~m}$ agree very well, at least after 11:45 UTC. At the same time, the cross correlation mainly gives negative values, if it is calculated between the time series of vertical velocity for Selhausen and Hambach or between Selhausen and Wasserwerk (not shown).

In contrast to 18 and 24 April, the mean wind direction on 20 April is northeast. On this day, large differences of $\overline{w^{\prime 2}}$ max are observed between Hambach and Wasserwerk in the afternoon. The cross correlation function also shows very low correlations $(<0.1$; not shown).

The mean wind direction may thus be one explanation why differences between the variances at Wasserwerk and Hambach are small on 18 and 24 April, but significant on 20 April (Fig. 10), although similar surface conditions exist on all of these days: the diurnal cycles of variances are similar at the two sites when the mean wind is parallel to their connecting axis, but different otherwise. For the time periods when the correlation between the two sites is high, the correlation between the third site and each of the two is low. It is remarkable that on 24 April, when convective cells are 


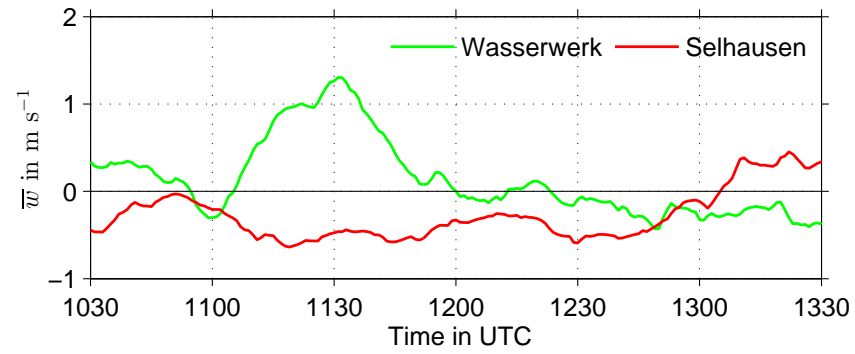

Figure 15. Mean vertical velocity (running average of $60 \mathrm{~min}$ ) at $700 \mathrm{~m}$ ( \pm 1 range gate) at Wasserwerk and Selhausen on 24 April.

advected past Wasserwerk and Hambach without substantial changing, the mean vertical velocity (Fig. 15) is positive at Wasserwerk between 11:00-12:00 UTC (more than $1 \mathrm{~m} \mathrm{~s}^{-1}$ ) and negative at Selhausen (11:00-13:00 UTC, i.e., even for $2 \mathrm{~h}$ ). We hypothesize that, while many cells are observed on the northern axis, less occur about $3 \mathrm{~km}$ further south due to the subsidence in the surroundings of the cells. This assumption is confirmed by model simulations for 24 April with the Consortium for Small-scale Modeling (COSMO) model in LES mode. They were performed on a grid with $100 \mathrm{~m}$ horizontal resolution using a 3-D-turbulence parameterization by Herzog et al. (2002). Model analyses of the operational model COSMO-DE (Baldauf et al., 2011) provided atmospheric initial and boundary conditions. The vertical velocity as calculated by the model is shown on a horizontal cross section at $600 \mathrm{~m}$ (Fig. 16). The instantaneous as well as the field averaged over $1 \mathrm{~h}$ is given. About $1-1.5 \mathrm{~km}$ south and north of the regions where the mean vertical velocity is positive on the hourly average, which is caused by convective cells advected with the mean wind, subsidence prevails. As shown by Lenschow and Stephens (1982), the mean $w$ within thermals is positive and nearly 2 times higher than in the environment, where it is negative. This agrees very well with the mean $w$ observed at the different locations on 24 April (Fig. 15). The spatial variance differences on 18 and 24 April can therefore be explained by the occurrence of organized structures of turbulence: while more convective cells travel past the Wasserwerk as well as past Hambach, subsidence in the surroundings of these cells prevails at Selhausen. This structure is presumably the signature of horizontal rolls that develop during conditions of combined surface heating and strong winds (Stull, 1988, Ch. 11.2), as was observed by Brown (1970) or Kropfli and Kohn (1978).

On 20 April, mean wind comes from the northeast, so that thermals traveling from Hambach to Selhausen may be observed. However, this is not the case, and $w$ variance at both other sites differs from the one at Hambach (Fig. 10). One possible explanation is that, on days with easterly wind, the strongest influence of the open-pit coal mine on $w$ variance occurs at Hambach.

\section{Summary and conclusions}

During the HOPE campaign, multiple Doppler lidars were operated simultaneously at three different sites in the vertical stare mode to retrieve temporally high-resolved vertical velocity measurements. For this study, profiles of vertical velocity variance were derived for the three sites to investigate the spatiotemporal heterogeneity of turbulence in the cloudfree CBL. The aims were to analyze temporal variability as well as scaling of variance profiles and to compare the variance profiles for the different sites. It was investigated if spatial differences were statistically significant and if they depended on surface conditions, atmospheric conditions or on the averaging intervals.

The investigated area was characterized by patchy agricultural land use. The typical size of the crop fields was of the order of $100 \mathrm{~m}$. The 8 weeks of the measurement period were divided into a drier period (mid-April to 6 May) and a wetter one (starting on 7 May). The Bowen ratio varied between 0.5 and 4 during the drier period, while it was $<1$ at all stations during the wetter period. Five of the six days selected for this study fell into the drier period.

Boundary-layer mixing was strong on all of the selected days and the height of the CBL was between 1.2 and $2 \mathrm{~km}$. Different methods to derive $z_{i}$ (radiosonde profiles, aerosol backscatter, $w$-variance profiles) agreed well in most cases. Only when a residual layer was present above the CBL, lower values were derived from $w$-variance profiles than by the other methods. Finally, $z_{i}$ values from the aerosol backscatter were used, because it was the only method that yielded values for all time steps. On 3 of the days, clouds occurred, but the diurnal cycle of incoming radiation was only slightly affected on 18 April, when some boundary-layer clouds were present and on 19 May, when mid-level clouds were observed. There were cirrus clouds on 24 April which did not perceptibly reduce incoming radiation. Moderate westerly wind dominated on most days; on 18 April, the mean horizontal wind was stronger than on the other days and it came from the northeast on 20 April and 19 May.

The combination of smaller and larger Doppler lidars with complementary measurements at different heights proved to be beneficial for the investigations. For the calculation of higher-order moments of $w$, different aspects were considered: (1) the random noise of the signal ("uncorrelated noise") was removed, (2) the lack of spectral contribution to the total energy caused by spatial averaging of the lidar measurement was neglected, and (3) the statistical errors (systematic and sampling error according to Lenschow et al., 1994) that appear due to the spatial and temporal subsampling were provided. Moreover, as measurements by lidar instruments from different manufacturers were compared here, also the instrument-dependent differences were calculated.

For the scaling of the $w$-variance profiles, representative surface fluxes were needed. The relevant length scale was 
(a) $w$ at 1230 UTC

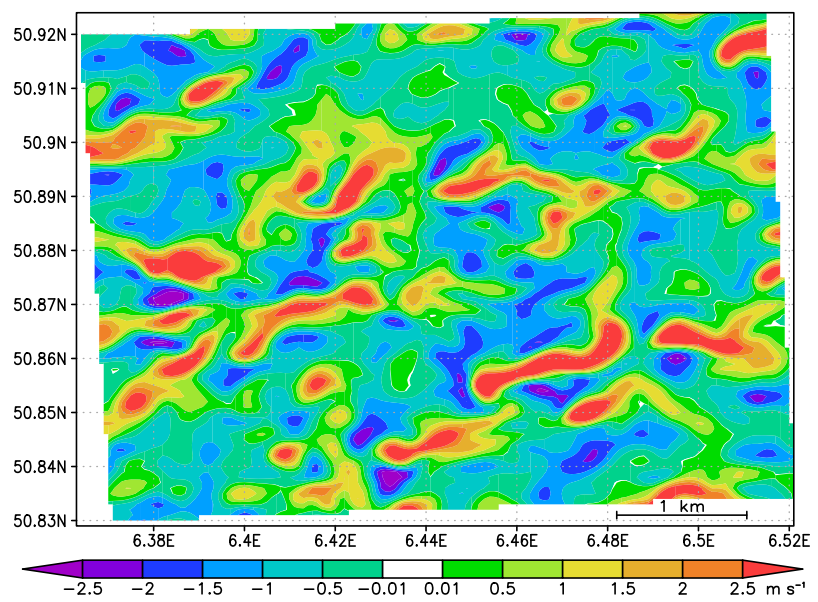

(b) $w$ averaged between 1200 and 1300 UTC

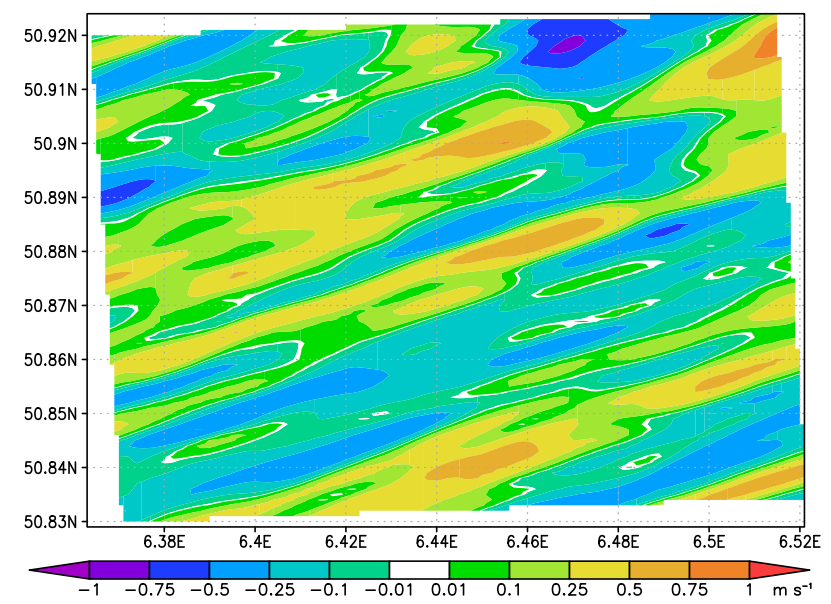

Figure 16. Vertical velocity at $600 \mathrm{~m}$ on 24 April 2013 from LES model output: (a) instantaneous, (b) averaged field.

estimated according to $\Delta t \cdot|\boldsymbol{v}|$, which is about $15 \mathrm{~km}$ for an averaging interval of $1 \mathrm{~h}$ and a mean wind speed of $4 \mathrm{~m} \mathrm{~s}^{-1}$. Weighted-averaged values of $w_{*}$ were derived for an area of $30 \mathrm{~km} \times 30 \mathrm{~km}$ with the lidars in its center. Additionally, $w_{*}$ was calculated using fluxes from the individual energy balance stations near the three sites. On average, scaled profiles at the three locations agreed well with those shown by Willis and Deardorff (1974), Caughey and Palmer (1979) or Lenschow et al. (1980). However, they showed large scatter at individual locations, and the standard deviation was larger than the statistical error in most cases. The relative difference between both was between 5 and $34 \%$. In a similar investigation, Lenschow et al. (2012) found a relative difference of about $10 \%$.

Evaluating the correlations between $w_{*}$ and vertically averaged values of $w$ variance, it turned out that the choice of the energy balance station that provides sensible heat fluxes was crucial for local scaling. The correlations varied between $R^{2}=0.28$ and 0.72 , i.e., local scaling could be completely inappropriate to describe the upstream conditions determining the CBL turbulence at the lidar site. Therefore, the use of weighted-averaged fluxes is preferable for scaling $\left(R^{2}\right.$ between 0.46 and 0.50). Unexplained temporal variance of $w$ variance could not be related to the temporal variability of wind shear, mean wind speed or of the Obukhov length.

Thus, time series of $w$ were analyzed for two cases which contributed significantly to the unexplained temporal variance. In one case, the high variance was caused by an increased relative frequency of strong up- and downdrafts, and in the other one by broader thermals. Broad and strong thermals may additionally have caused the elevated maximum of $w$ variance.

Statistically significant spatial differences were found by comparing vertically averaged values of vertical velocity variance at the three sites. They also occurred on days with westerly to southwesterly wind, when the influence of a large open-pit coal mine in the surroundings was presumably low. To investigate whether these differences were generated by heterogeneous surface conditions, local scaling was applied. The results implied that the heterogeneity of the surface conditions could not be the main reason.

Secondly, the influence of different averaging intervals on the spatial differences of $w$ variance was analyzed. Relative deviations of $w$ variances between all instruments averaged over all days as well as statistical errors decreased strongly with increasing averaging intervals. Thus, mean relative deviations were about as large as the relative statistical errors for all averaging intervals. On the other hand, relative deviations of variances at different sites were about 3 times higher than between those derived from measurements by different lidars at the same site. Postulating that the uncertainty of a point measurement should not be larger than $10 \%$, measurement periods of at least $3 \mathrm{~h}$ are necessary.

Finally, a detailed analysis of periods with significant spatial differences of $w$ variance provided some insight into possible reasons: it was found that a varying degree of correlation between vertical velocity fluctuations existed for two locations on an east-west axis. On 18 April, a day with stronger west-southwesterly wind, and on 24 April with moderate wind speed, the travel time was smaller than the large-eddy turnover time. On these days, fluctuations and variances were similar at the two locations, while the correlation of both with fluctuations at the third location about $2.5 \mathrm{~km}$ further south was low. Simultaneously, the mean vertical velocity was positive at the first two sites, while it was negative at the third location for a time period of $2 \mathrm{~h}$. The reason is that several convective cells traveled past the first two sites, while subsidence prevailed at the third site during the whole $2 \mathrm{~h}$ period. The presence of organized structures of turbulence, which is also confirmed by LES, explains why spatial variance differ- 
ences existed and did not disappear even for averaging periods of more than $3 \mathrm{~h}$.

Based on these findings, the following conclusions can be drawn: (1) the representativeness of single-column turbulence characteristics as observed by Doppler lidars is not necessarily given, even if long time periods are available (with the maximum possible length of the time period being the whole part of day with an existing CBL); (2) local scaling with $w_{*}$ is possible but should only be considered, if the representativeness of an individual energy balance station for a larger area is proven; and (3) organized structures of turbulence in the CBL such as horizontal rolls aligned with the mean wind may be the reason for statistically significant spatial differences of vertical velocity variances. 


\section{Appendix A: Error statistics}

\section{A1 Uncorrelated noise}

The so-called "uncorrelated noise" defined by Lenschow et al. (2000) is based on the assumption that the measurement signal is "contaminated by uncorrelated random noise". By definition, it is uncorrelated from the signal and the respective error can, thus, be removed from the calculated variance. According to Eq. (8) from Lenschow et al. (2000), the uncorrelated-noise error is equal to the difference between the first and zero lag of the autocovariance function.

\section{A2 Systematic error}

According to Lenschow et al. (1994), the statistical error can be separated into the systematic and the random error (see Appendix A3). The systematic error is caused by the fact that the variance $\overline{w^{\prime 2}}$ derived from the measurement is, strictly speaking, a time average ${\overline{w^{\prime 2}}}^{t}$, which is not equal to the ensemble average ${\overline{w^{\prime 2}}}^{t, x}$. With these definitions, equation (14) from Lenschow et al. (1994) is

$\frac{{\overline{w^{\prime 2}}}^{t, x}}{{\overline{w^{\prime 2}}}^{t}} \approx 1-2 \frac{\widetilde{T}}{\Delta t}$,

with the averaging time $\Delta t$ and the integral time scale $\widetilde{T}$ (see Appendix B). The absolute value of the systematic error can, thus, be calculated as

$\left|{\overline{w^{\prime 2}}}^{t, x}-{\overline{w^{\prime 2}}}^{t}\right|={\overline{w^{\prime 2}}}^{t} \cdot 2 \frac{\widetilde{T}}{\Delta t}$.

From this, it can be seen that the systematic error increases for increasing integral time scales, decreasing averaging periods as well as with the variance itself.

\section{A3 Random error}

The random or sampling error takes into account that the length of the measured time series is not unlimited and that "random" time slots may differ. Lenschow et al. (1994) show that, using the error variance $\sigma_{2}^{2}$ for the second moment, the random error can be approximated to

$\sigma_{2}={\overline{w^{\prime 2}}}^{t} \cdot \sqrt{2 \frac{\widetilde{T}}{\Delta t}}$

The ratio of the systematic to the random error can, thus, be determined as $\sqrt{2 \frac{\widetilde{T}}{\Delta t}}$. For the commonly used averaging time of $1 \mathrm{~h}$ and a typical integral time scale of about $50 \mathrm{~s}$ (in this study, which agrees with numbers from Lothon et al., 2006, for example), this expression amounts to 0.17 . This means that in this case, the random error is more than 5 times higher than the systematic error. Only for distinctly larger integral time scales, i.e., $\widetilde{T} \geq 450 \mathrm{~s}$, does the systematic error become higher than the random error for the $1 \mathrm{~h}$ averaging period.

\section{Appendix B: Integral time scale}

Going back to Lumley and Panofsky (1964), the integral time scale is defined as the integral of the autocorrelation function $R$. Here, it was calculated as the integral between lag zero determined by extrapolation (Lenschow et al., 2000) and the first zero-crossing of $R$. 
Acknowledgements. This work was funded by the Federal Ministry of Education and Research in Germany (BMBF) under the research program "High Definition Clouds and Precipitation for Climate Prediction "HD $(\mathrm{CP})^{2}$ " (FKZ: 01LK1212F). We want to thank Marius Schmidt from Forschungszentrum Jülich for providing surface fluxes from the energy balance stations that were operated within the framework of TERENO. Furthermore, Mauro Sulis and Prabhakar Shrestha from University of Bonn provided the land-use data. Katja Träumner and the Young Investigator Group "Coherent structures" contributed to the operation of the Doppler lidars during the HOPE experiment and made their analysis tools available, including functions for error calculations. We are also grateful to the whole IMK team for their efforts in deploying KITcube. Finally, the helpful comments of two anonymous reviewers are appreciated.

The article processing charges for this open-access publication were covered by a Research

Centre of the Helmholtz Association.

Edited by: H. Russchenberg

\section{References}

Angevine, W. M., Doviak, R. J., and Sorbjan, Z.: Remote sensing of vertical velocity variance and surface heat flux in a convective boundary layer, J. Appl. Meteor., 33, 977-983, 1994.

Ansmann, A., Fruntke, J., and Engelmann, R.: Updraft and downdraft characterization with Doppler lidar: cloud-free versus cumuli-topped mixed layer, Atmos. Chem. Phys., 10, 78457858, doi:10.5194/acp-10-7845-2010, 2010.

Baldauf, M., Seifert, A., Förstner, J., Majewski, D., Raschendorfer, M., and Reinhardt, T.: Operational convective-scale numerical weather prediction with the COSMO model: description and sensitivities, Mon. Wea. Rev., 139, 3887-3905, 2011.

Beyrich, F. and Mengelkamp, H.-T.: Evaporation over a heterogeneous land surface: EVA_GRIPS and the LITFASS-2003 experiment - an overview, Boundary-Layer Meteorol., 121, 5-32, 2006.

Brown, R. A.: A secondary flow model for the planetary boundary layer, J. Atmos. Sci., 27, 742-757, 1970.

Browning, K. and Wexler, R.: The determination of kinematic properties of a wind field using Doppler radar, J. Appl. Meteor., 7, 105-113, 1968.

Cañadillas, B., Westerhellweg, A., and Neumann, T.: Testing the performance of a ground-based wind LiDAR system: One year intercomparison at the offshore platform FINO1, DEWI Mag., 38, 58-64, 2011.

Caughey, S. J. and Palmer, S. G.: Some aspects of turbulence structure through the depth of the convective boundary layer, Q. J. R. Meteorol. Soc., 105, 811-827, 1979.

Darbieu, C., Lohou, F., Lothon, M., Vilà-Guerau de Arellano, J., Couvreux, F., Durand, P., Pino, D., Patton, E. G., Nilsson, E., Blay-Carreras, E., and Gioli, B.: Turbulence vertical structure of the boundary layer during the afternoon transition, Atmos. Chem. Phys., 15, 10071-10086, doi:10.5194/acp-1510071-2015, 2015.
Deardorff, J. W.: Preliminary results from numerical integrations of the unstable planetary boundary layer, J. Atmos. Sci., 27, 12091211, 1970a.

Deardorff, J. W.: Convective velocity and temperature scales for the unstable planetary boundary layer and for Rayleigh convection, J. Atmos. Sci., 27, 1211-1213, 1970b.

Deardorff, J. W.: Three-dimensional numerical study of the height and mean structure of a heated planetary boundary layer, Boundary-Layer Meteorol., 7, 81-106, 1974.

Eder, F., Schmidt, M., Damian, T., Träumner, K., and Mauder, M.: Mesoscale eddies affect near-surface turbulent exchange: Evidence from lidar and tower measurements, J. Appl. Meteor., 54, 189-206, 2015.

Emeis, S., Schäfer, K., and Münkel, C.: Surface-based remote sensing of the mixing-layer height - a review, Meteorol. Z., 17, 621630, 2008.

Eng, K., Coulter, R. L., and Brutsaert, W.: Vertical velocity variance in the mixed layer from radar wind profilers, J. Hydrol. Eng., 8, 301-307, 2003.

Eymard, L. and Weill, A.: Dual Doppler radar investigation of the tropical convective boundary layer, J. Atmos. Sci., 45, 853-864, 1988.

Frehlich, R., Hannon, S., and Henderson, S.: Coherent Doppler lidar measurements of wind field statistics, Boundary-Layer Meteorol., 86, 233-256, 1998.

Graf, A., Schüttemeyer, D., Geiß, H., Knaps, A., Möllmann-Coers, M., Schween, J. H., Kollet, S., Neininger, B., Herbst, M., and Vereecken, H.: Boundedness of turbulent temperature probability distributions, and their relation to the vertical profile in the convective boundary layer, Boundary-Layer Meteorol., 134, 459486, 2010.

Hadfield, M., Cotton, W., and Pielke, R.: Large-eddy simulations of thermally forced circulations in the convective boundary layer. Part I: A small-scale circulation with zero wind, Boundary-Layer Meteorol., 57, 79-114, 1991.

Herzog, H.-J., Vogel, G., and Schubert, U.: LLM - a nonhydrostatic model applied to high-resolving simulations of turbulent fluxes over heterogeneous terrain, Theor. Appl. Climatol., 73, 67-86, 2002.

Hogan, R. J., Grant, A. L., Illingworth, A. J., Pearson, G. N., and O'Connor, E. J.: Vertical velocity variance and skewness in clear and cloud-topped boundary layers as revealed by Doppler lidar, Q. J. R. Meteorol. Soc., 135, 635-643, 2009.

Kaimal, J. C., Wyngaard, J. C., Haugen, D. A., Coté, O. R., Izumi, Y., Caughey, S. J., and Readings, C. J.: Turbulence structure in the convective boundary layer, J. Atmos. Sci., 33, 2152-2169, 1976.

Kalthoff, N., Adler, B., Wieser, A., Kohler, M., Träumner, K., Handwerker, J., Corsmeier, U., Khodayar, S., Lambert, D., Kopmann, A., Kunka, N., Dick, G., Ramatschi, M., Wickert, J., and Kottmeier, C.: KITcube - a mobile observation platform for convection studies deployed during HyMeX, Meteorol. Z., 22, 633 647, 2013.

Kropfli, R. and Kohn, N.: Persistent horizontal rolls in the urban mixed layer as revealed by dual-Doppler radar, J. Appl. Meteor., 17, 669-676, 1978.

Lenschow, D. H. and Stankov, B. B.: Length scales in the convective boundary layer, J. Atmos. Sci., 43, 1198-1209, 1986. 
Lenschow, D. H. and Stephens, P. L.: The role of thermals in the convective boundary layer, Boundary-Layer Meteorol., 19, 509_ 532, 1980.

Lenschow, D. H. and Stephens, P. L.: Mean vertical velocity and turbulence intensity inside and outside thermals, Atmos. Environ., 16, 761-764, 1982.

Lenschow, D. H., Wyngaard, J. C., and Pennell, W. T.: Mean-field and second-moment budgets in a baroclinic, convective boundary layer, J. Atmos. Sci., 37, 1313-1326, 1980.

Lenschow, D. H., Mann, J., and Kristensen, L.: How long is long enough when measuring fluxes and other turbulence statistics?, J. Atmos. Oceanic Technol., 11, 661-673, 1994.

Lenschow, D. H., Wulfmeyer, V., and Senff, C.: Measuring secondthrough fourth-order moments in noisy data, J. Atmos. Oceanic Technol., 17, 1330-1347, 2000.

Lenschow, D. H., Lothon, M., Mayor, S. D., Sullivan, P. P., and Canut, G.: A comparison of higher-order vertical velocity moments in the convective boundary layer from lidar with in situ measurements and large-eddy simulation, Boundary-Layer Meteorol., 143, 107-123, 2012.

Lothon, M., Lenschow, D. H., and Mayor, S. D.: Coherence and scale of vertical velocity in the convective boundary layer from a Doppler lidar, Boundary-Layer Meteorol., 121, 521-536, 2006.

Lothon, M., Lenschow, D. H., and Mayor, S. D.: Doppler lidar measurements of vertical velocity spectra in the convective planetary boundary layer, Boundary-Layer Meteorol., 132, 205-226, 2009.

Lumley, J. L. and Panofsky, H. A.: The structure of atmospheric turbulence, Interscience monographs and texts in physics and astronomy ; 12, Interscience Publ., New York, NY, 239 pp., 1964.

Mahrt, L.: Flux sampling errors for aircraft and towers, J. Atmos. Oceanic Technol., 15, 416-429, 1998.

Mauder, M. and Foken, T.: Documentation and instruction manual of the eddy-covariance software package TK3, Abteilung Mikrometeorologie: Arbeitsergebnisse 46, ISSN 1614-8924, 60 pp., 2011.

Mauder, M., Cuntz, M., Drüe, C., Graf, A., Rebmann, C., Schmid, H. P., Schmidt, M., and Steinbrecher, R.: A strategy for quality and uncertainty assessment of long-term eddy-covariance measurements, Agric. Forest Meteorol., 169, 122-135, 2013.

Moeng, C.-H.: A large-eddy-simulation model for the study of planetary boundary-layer turbulence, J. Atmos. Sci., 41, 2052-2062, 1984.

Monin, A. S. and Obukhov, A. M.: Basic laws of turbulent mixing in the surface layer of the atmosphere, Contrib. Geophys. Inst. Acad. Sci. USSR, 151, 163-187, 1954.

Neggers, R. A. J., Duynkerke, P. G., and Rodts, S. M. A.: Shallow cumulus convection: A validation of large-eddy simulation against aircraft and Landsat observations, Q. J. R. Meteorol. Soc., 129, 2671-2696, 2003.

Panofsky, H. A. and Mazzola, C.: Variances and spectra of vertical velocity just above the surface layer, Boundary-Layer Meteorol., 2, 30-37, 1971.

Pearson, G., Davies, F., and Collier, C.: An analysis of the performance of the UFAM pulsed Doppler lidar for observing the boundary layer, J. Atmos. Oceanic Technol., 26, 240-250, 2009.
Pospichal, B. and Crewell, S.: Boundary layer observations in West Africa using a novel microwave radiometer, Meteorol. Z., 16, 513-523, 2007.

Schröter, M., Bange, J., and Raasch, S.: Simulated airborne flux measurements in a LES generated convective boundary layer, Boundary-Layer Meteorol., 95, 437-456, 2000.

Sorbjan, Z.: On similarity in the atmospheric boundary layer, Boundary-Layer Meteorol., 34, 377-397, 1986.

Sorbjan, Z.: Local similarity in the convective boundary layer (CBL), Boundary-Layer Meteorol., 45, 237-250, 1988.

Sorbjan, Z.: Structure of the atmospheric boundary layer, Prentice Hall, Englewood Cliffs, New Jersey, 317 pp., 1989.

Steinfeld, G., Letzel, M., Raasch, S., Kanda, M., and Inagaki, A.: Spatial representativeness of single tower measurements and the imbalance problem with eddy-covariance fluxes: results of a large-eddy simulation study, Boundary-Layer Meteorol., 123, 77-98, 2007.

Stull, R. B.: An introduction to boundary layer meteorology, Atmospheric sciences library ; 13, Kluwer, Dordrecht, Netherlands, 666 pp., 1988.

Taylor, G. I.: The spectrum of turbulence, in: Proceedings of the Royal Society of London A: Mathematical, Physical and Engineering Sciences, vol. 164, The Royal Society, 476-490, 1938.

Träumner, K., Kottmeier, C., Corsmeier, U., and Wieser, A.: Convective boundary-layer entrainment: Short review and progress using Doppler lidar, Boundary-Layer Meteorol., 141, 369-391, 2011.

Tucker, S. C., Senff, C. J., Weickmann, A. M., Brewer, W. A., Banta, R. M., Sandberg, S. P., Law, D. C., and Hardesty, R. M.: Doppler lidar estimation of mixing height using turbulence, shear, and aerosol profiles, J. Atmos. Oceanic Technol., 26, 673-688, 2009.

van Heerwaarden, C. C., Mellado, J. P., and De Lozar, A.: Scaling laws for the heterogeneously heated free convective boundary layer, J. Atmos. Sci., 71, 3975-4000, 2014.

Warner, J.: The structure and intensity of turbulence in air over the sea, Q. J. R. Meteorol. Soc., 98, 175-186, 1972.

Willis, G. E. and Deardorff, J. W.: A laboratory model of the unstable planetary boundary layer, J. Atmos. Sci., 31, 1297-1307, 1974.

Wyngaard, J. C., Coté, O. R., and Izumi, Y.: Local free convection, similarity, and the budgets of shear stress and heat flux, J. Atmos. Sci., 28, 1171-1182, 1971.

Young, G. S.: Turbulence structure of the convective boundary layer. Part I. Variability of normalized turbulence statistics, J. Atmos. Sci., 45, 719-726, 1988.

Zacharias, S., Bogena, H., Samaniego, L., Mauder, M., Fuß, R., Pütz, T., Frenzel, M., Schwank, M., Baessler, C., ButterbachBahl, K., Bens, O., Borg, E., Brauer, A., Dietrich, P., Hajnsek, I., Helle, G., Kiese, R., Kunstmann, H., Klotz, S., Munch, J. C., Papen, H., Priesack, E., Schmid, H. P., Steinbrecher, R., Rosenbaum, U., Teutsch, G., and Vereecken, H.: A network of terrestrial environmental observatories in Germany, Vadose Zone J., 10, 955-973, 2011. 